\title{
Wheel Setting Error Modelling and Compensation for Arc Envelope Grinding of Large-aperture Aspherical Optics
}

\section{Changsheng Li ( $\square$ 791226648@qq.com )}

Xi'an Jiaotong University https://orcid.org/0000-0002-4119-5823

\section{Lin Sun}

Xi'an Jiaotong University

\section{Zhaoxiang Chen}

Xi'an Jiaotong University

Jianfang Chen

Xi'an Jiaotong University

Qijing Lin

Xi'an Jiaotong University

Jianjun Ding

Xi'an Jiaotong University

\section{Zhuangde Jiang}

Xi'an Jiaotong University

\section{Original Article}

Keywords: aspherical optics, large-aperture optics, wheel setting, arc envelope grinding, form error

Posted Date: January 11th, 2021

DOl: https://doi.org/10.21203/rs.3.rs-141376/v1

License: (9) This work is licensed under a Creative Commons Attribution 4.0 International License. Read Full License 


\title{
Wheel setting error modelling and compensation for arc envelope grinding of large-aperture aspherical optics
}

\author{
Changsheng Li ${ }^{\text {a, b }}$, li.changsheng@xjtu.edu.cn \\ Lin Sun ${ }^{\mathrm{a}, \mathrm{b}, *}$, sunlin@xjtu.edu.cn \\ Zhaoxiang Chen ${ }^{\mathrm{b}}$, chenzhaoxiang@xjtu.edu.cn \\ Jianfang Chen ${ }^{\mathrm{c}}$, cjf20100@163.com \\ Qijing Lin ${ }^{\mathrm{a}, \mathrm{b}}$, qjlin2015@mail.xjtu.edu.cn \\ Jianjun Ding a, b, dianjianjun@126.com \\ Zhuangde Jiang a, b, zdjiang@ mail.xjtu.edu.cn
}

a State Key Laboratory for Manufacturing Systems Engineering, Xi'an Jiaotong University, Xi'an, Shaanxi 710049, China

b School of Mechanical Engineering, Xi'an Jiaotong University, Xi'an, Shaanxi 710049, China

c Shaanxi Qinchuan Precision CNC Machine Tool Engineering Research Co., Xi'an, Shaanxi 710018, China

*Corresponding authors: Lin Sun, E-mail: sunlin@xjtu.edu.cn 


\begin{abstract}
Precision grinding is the key process to meet the heavy demands of large-aperture aspherical optical elements in the fields of laser nuclear fusion devices, large-aperture astronomical telescopes and high-resolution space cameras. In this study, the arc envelope grinding process of large-aperture aspherical optics was investigated using the CM1500 precision grinding machine with a maximum machinable diameter of $\Phi 1500 \mathrm{~mm}$. The analytical form error models of aspherical workpiece induced by wheel setting errors were established for both parallel grinding and cross grinding. Result show that the form error is much more sensitive to the wheel setting error along the feed direction than that along the lateral direction. It is a bilinear function of the feeddirection wheel setting error and the distance to optical axis. Based on the above analysis, a method to determine the wheel setting error is proposed. The grinding tests were then performed with the wheel accurately aligned. By using a newly proposed partial error compensation method with an appropriate compensation factor, a form error of $3.4 \mu \mathrm{m}$ PV for a $\Phi 400 \mathrm{~mm}$ elliptical K9 glass surface was achieved.
\end{abstract}

Keywords: aspherical optics, large-aperture optics, wheel setting, arc envelope grinding, form error

\title{
1. Introduction
}

Laser nuclear fusion devices, large-aperture astronomical telescopes, high-resolution earth observation systems, and IC lithography machines have great demands on large ultra-precision aspheric optical elements, and their diameter and accuracy restrict the development of related fields. For example, the primary mirrors of the Thirty Meter Telescope (TMT) (Usuda et al., 2014) and the $42 \mathrm{~m}$ European Extremely Large Telescope (E-ELT) (Gray et al., 2016) consist of 492 and 798 quasi-hexagonal mirror segments, respectively, with a diagonal length of $1.45 \mathrm{~m}$. The National Ignition Facility (NIF) (Campbell et al., 2004) in USA and the Megajoule Laser (LMJ) (André, 1999) in 
French requires $7360(500 \sim 1000 \mathrm{~mm})$ and $4200(810 \times 460 \mathrm{~mm})$ pieces of large-aperture optical elements, respectively. Typical manufacturing process of aspheric optical elements consists of grinding, polishing and focused ion beam (FIB) figuring. The material removal rate of the polishing and figuring processes are extremely low. Therefore, the form error and subsurface damage depth induced by the grinding of aspheric optics should be reduced to reduce the required material removal depth in the subsequent processes.

Driven by the above demands, the United States, the United Kingdom and France have achieved considerable technological advancements on the ultra-precision machining of large-aperture mirrors. The Steward Laboratory in the University of Arizona developed the Large Optical Generator (LOG) that can grind and polish $8 \mathrm{~m}$-scale mirrors (Parks, Lam, \& Kuhn, 1985). It was successfully used to machine the $6.5 \mathrm{~m}$ primary mirror of the Magellan telescope (Martin et al., 2003) and the $8.4 \mathrm{~m}$ primary mirrors of the Large Binocular Telescope (LBT) (Martin et al., 2003; West et al., 1994). The form error of these mirrors can be reduced to below $10 \mu \mathrm{m}$ RMS after grinding. Cranfield University developed a large ultra-precision grinding machine, i.e., OAGM2500 (Comley, Morantz, Shore, \& Tonnellier, 2011; P Shore et al., 2005; Paul Shore \& Parr-Burman, 2004), for the manufacturing of large mirrors used in telescopes. Its maximum machinable aperture and achievable relative form error is $\Phi 2500 \mathrm{~mm}$ and $1 / 10^{6} \mathrm{PV}$, respectively. In order to improve the manufacturing efficiency of the mirror segments of E-ELT, Cranfield University proposed a rapid manufacturing process chain. The key of this process is using the large ultra-precision grinding machine, i.e., Big OptiX (BOX) (Comley et al., 2011; P Shore et al., 2005), to achieve the ultra-precision, highefficiency and low-damage grinding of hard-and-brittle materials. By employing a novel $R$-theta grinding mode with an inclined toroidal shape diamond wheel, a high material removal rate of $187.5 \mathrm{~mm}^{3} / \mathrm{s}$ was achieved when grinding the $1.45 \mathrm{~m}$ Zerodur mirror (Comley et al., 2011). The RMS form error and subsurface damage depth can be 
reduced to below $1 \mu \mathrm{m}$ within the manufacturing cycle of $<20 \mathrm{~h}$. The ULTRASONIC100-5 machining center developed by DMG MORI Company Ltd. integrates ultrasonic vibration with traditional grinding. As a result, the RMS form error of a $700 \mathrm{~mm} \times 700 \mathrm{~mm} \mathrm{SiC} \mathrm{high-order} \mathrm{off-axis} \mathrm{aspheric} \mathrm{mirror} \mathrm{was} \mathrm{efficiently} \mathrm{reduced}$ to $2.13 \mu \mathrm{m}$ (Zhang, Li, Zheng, \& Zhang, 2013). Some other German companies, e.g., Blohm, Satisloh, Schneider and Optotech also provide large aspheric grinding machines with a machinable diameter of $\Phi 500 \mathrm{~mm}$ - $\Phi 2000 \mathrm{~mm}$.

China have also conducted in-depth study on the ultra-precision grinding of largeaperture optics in these years. For example, Tsinghua University developed a six-axis large-scale precision grinding machine. Grinding tests of a $\Phi 770 \mathrm{~mm} \mathrm{~K} 9$ glass show that form error can be smaller than $10 \mu \mathrm{m}$ and surface roughness can reach sub-micron level. The AOCMT ultra-precision grinding machine (G. Wang, Li, \& Dai, 2004) developed by the National University of Defense Technology can machine optical elements with a diameter of $650 \mathrm{~mm}$. It has been successfully used to grind a $\Phi 116 \mathrm{~mm}$ parabolic SiC workpiece to the form error of $8.9 \mu \mathrm{m}$. Changchun Institute of Optics and Fine Mechanics has developed a series of four-axis aspheric machine tools, e.g., the 800 mm-scale FSGJ-1 (Xuejun, Yunfeng, Jingchi, \& Zhongyu, 1997), the $1.2 \mathrm{~m}$-scale FSGJ-2 (Feng et al., 2008) and the 2 m-scale FSGJ-3, which integrate the functions of rough grinding, fine grinding, polishing and online measurement. By using the Computer-Controlled Optical Polishing (CCOP) technique, the form precision of 12 nm RMS for $1 \mathrm{~m}$-scale mirrors was achieve. In recent years, Xi'an Jiaotong University has developed two ultra-precision aspheric grinding machines with maximum machinable diameter of $\Phi 900$ mm (Bin, Jianpu, Dongxu, Zexiang, \& Zhao, 2019; Xi, Zhao, Li, \& Ren, 2016) and Ф1500 mm (Sun et al., 2017; Wei et al., 2018). By using the Arc Envelope Grinding Method (AEGM), the achievable form error is smaller than $5 \mu \mathrm{m}$ PV. 
During the grinding process of aspheric optical elements, tool setting error is one of the main error sources of the workpiece form error. Due to the form and dimension errors of the grinding wheel, and the installation errors of the wheel and workpiece, the wheel position cannot be simply determined by the nominal geometry of the wheel. Therefore, it is necessary to adjust the tool position in $X, Y$, and $Z$ directions during the grinding process. The tool setting in the $X$ and $Y$ directions makes the lowest point of the grinding wheel coincide the axis of the turntable. The tool setting in the $Z$ direction determines the height of the grinding wheel relative to the workpiece.

Though the tool setting problem has been intensively studied duo to its significance (Maeng \& Min, 2020; Y. Wang, Zhang, He, Tao, \& Feng, 2018), only a few literature on wheel setting can be found for the grinding of aspheric optics. Fengjun Chen et al. (Chen, Yin, Huang, \& Ohmori, 2015) found that an inward and outward offset will generate a $\mathrm{V}$-shaped and $\Lambda$-shaped profiles, respectively. However, the relationship between wheel setting error and the workpiece form error has not been analytically modelled. Xiang Wei et al. (Wei et al., 2018) and Jianpu Xi et al. (Xi et al., 2016) developed tool setting error models covering both the radial and lateral directions, but these models neglected the variation of the grinding point during the AEGM, which limits the prediction accuracy, especially for steep aspheric surfaces.

The outer cylindrical surface and upper plane of the workpiece are used as reference surfaces during the rough setting of the wheel. When the wheel is set in the $X$ direction, it approaches the outer cylindrical surface from both the positive and negative directions of the $X$ axis. The $X$ coordinates of the machine tool at the contact state are recorded as $x_{1}$ and $x_{2}$, respectively. The middle of $x_{1}$ and $x_{2}$ is the zero point of the workpiece in the $X$-direction, i.e., $x_{0}=\left(x_{1}+x_{2}\right) / 2$.

However, the accuracy of the above-mentioned wheel setting method is rather limited. 
This is because the form error of the cylindrical surface may be large and the contact state between the wheel and the workpiece is difficult to be accurately determined. Therefore, the evolution of workpiece form error with the wheel setting errors should be clarified to develop other methods.

\section{Modeling of aspherical surface generation}

\subsection{Geometric representation of aspherical surface}

An aspheric surface is a rotational-symmetrical surface that deviates from the spherical surface in shape. The spherical or aspherical surface with the vertex at the origin and the optical axis along the $Z$ axis can be described by

$$
z(h)=\frac{c h^{2}}{1+\sqrt{1-(1+k) c^{2} h^{2}}}+\sum A_{m} h^{2 m}
$$

where, $c=1 / R_{0}$ is the vertex curvature, and $R_{0}$ is the vertex curvature radius. $h$ is the radial distance the optical axis (see Fig. 1). $k$ is the conic constant. $A_{m} h^{2 m}$ represents the high-order terms of the aspherical surface where $m$ is an integer.

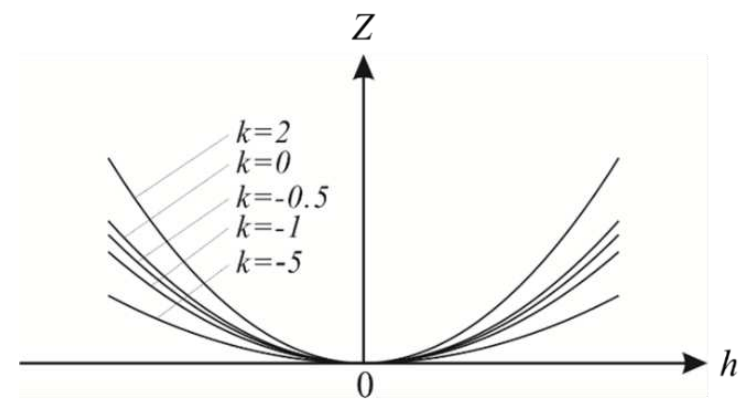

Fig. 1 Surfaces corresponding to different conic constants $k$

Eq. (1) represents a quadratic aspheric surface if the higher-order terms are absent. It can be rewritten as 


$$
\frac{\left(z-\frac{1}{(1+k) c}\right)^{2}}{\left(\frac{1}{(1+k) c}\right)^{2}}+\frac{h^{2}}{\left(\frac{1}{\sqrt{1+k} c}\right)^{2}}=1
$$

As shown in Fig. 1, the conic constant $k$ determines the shape of the surface, i.e.,

$$
\left\{\begin{array}{c}
k=0, \text { spherical surface } \\
k=-1, \text { paraboloid } \\
k>0, \text { oblate ellipsoid } \\
-1<k<0, \text { prolate ellipsoid } \\
k<-1, \text { hyperboloid }
\end{array}\right.
$$

For a point $P(x, y, z)$ on a quadratic aspherical surface (see Fig. 2), its coordinates can also be expressed as a parametric equation, i.e.,

$$
\left\{\begin{array}{c}
x=h \cos \theta \\
y=h \sin \theta \\
z=\frac{c h^{2}}{1+\sqrt{1-(1+k) c^{2} h^{2}}}
\end{array}\right.
$$

where $\theta$ is the angle between the positive direction of the $X$ axis and projected vector of $\stackrel{\text { umu }}{O P}$ on the $X O Y$ plane, as demonstrated in Fig. 2.

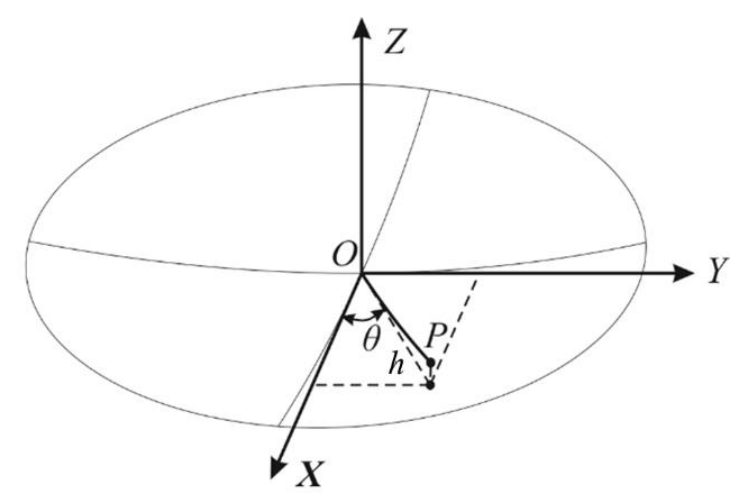

Fig. 2 Coordinate system of aspheric workpiece 


\subsection{Geometric representation of arc grinding wheel}

A parallel grinding wheel with circular arc is used for arc envelope grinding of aspheric optical elements. The coordinate system of the grinding wheel is shown in Fig. 3. The $Y^{\prime}$ axis is along the wheel axis, and the origin $O^{\prime}$ locates at the intersection of the $Y^{\prime}$ axis and the axial symmetrical surface of the wheel. The wheel radius in this symmetry plane, i.e., $X^{\prime} O^{\prime} Z$ coordinate plane, is $R$. The wheel surface with abrasive grains is rotationally symmetrical along the $Y^{\prime}$ axis. Its generatrix is an arc with a radius of $Q P^{\prime}=r$. The distance from the arc center $Q$ to the wheel axis is $a=R-r$. The distance from a point $P^{\prime}$ on the wheel surface to the $Y^{\prime}$ axis is taken as $l$. The angle between $P^{\prime} O^{\prime}$ and $X^{\prime} O^{\prime} Y^{\prime}$ plane is $\theta^{\prime}$ (clockwise) which ranges from 0 to $360^{\circ}$. The angle between the radius $Q P^{\prime}$ and the $X^{\prime} O^{\prime} Z$ plane is $\gamma^{\prime}$.

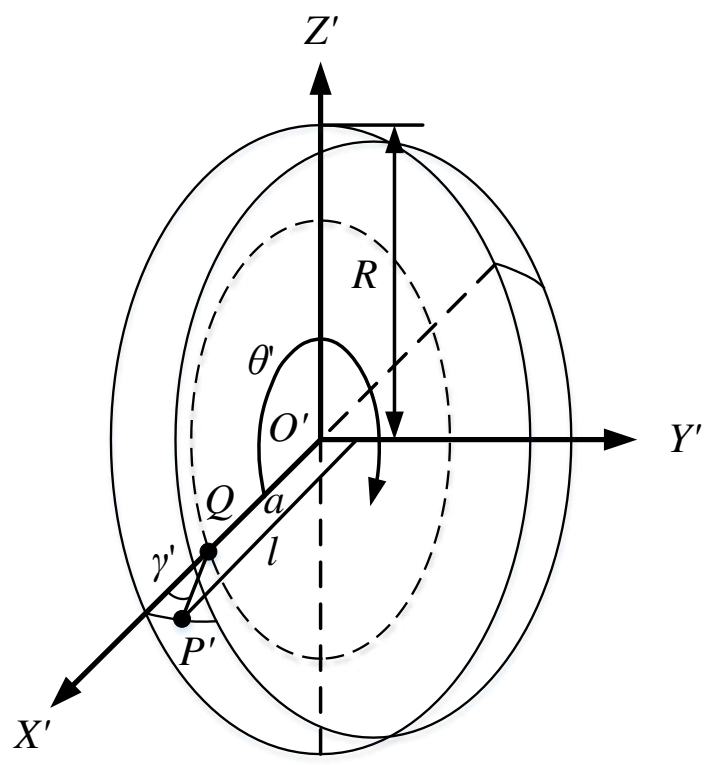

Fig. 3 Coordinate system of grinding wheel. Only the region of $Y^{\prime} \geq 0$ is shown because the wheel is symmetrical about the $X^{\prime} O^{\prime} Z^{\prime}$ plane

In the $O^{\prime} X^{\prime} Y^{\prime} Z$ coordinate system, the wheel surface can be described by the following parameter equations

$$
\begin{aligned}
& \left\{\begin{array}{l}
x^{\prime}=l \cos \theta^{\prime} \\
y^{\prime}=r \sin \gamma^{\prime} \\
z^{\prime}=l \sin \theta^{\prime}
\end{array}\right. \\
& l=a+r \cos \gamma^{\prime}
\end{aligned}
$$


The range of $\gamma^{\prime}$ is $-\arcsin \frac{W}{2 r} \leq \gamma^{\prime} \leq \arcsin \frac{W}{2 r}$, where $W$ is the width of the grinding wheel.

\subsection{Modeling of aspherical surface generation}

In order to model the generation process of the aspherical surface, the $Z$ axis of the workpiece coordinate system is assumed to coincide with the $Z$ axis of the wheel coordinate system, as shown in Fig. 4. The $X$ and $Y$ axes are parallel to the $X^{\prime}$ and $Y$ axes, respectively. The workpiece surface is tangent to the wheel surface during grinding, and the tangent point is referred to as the grinding point. The positions of the grinding point on both the wheel and workpiece are changing during grinding. The coordinates in the wheel coordinate system can be transformed into the workpiece coordinate system through the following translation transformation

$$
\left[\begin{array}{l}
x \\
y \\
z
\end{array}\right]=\left[\begin{array}{l}
x^{\prime} \\
y^{\prime} \\
z^{\prime}
\end{array}\right]+\boldsymbol{B}
$$

where $\boldsymbol{B}=\stackrel{\mathrm{Mm}}{O O^{\prime}}$ is the translation vector, which corresponds to the coordinates of $O^{\prime}$ in the workpiece coordinate system. As the programming point, its trajectory is the grinding path.

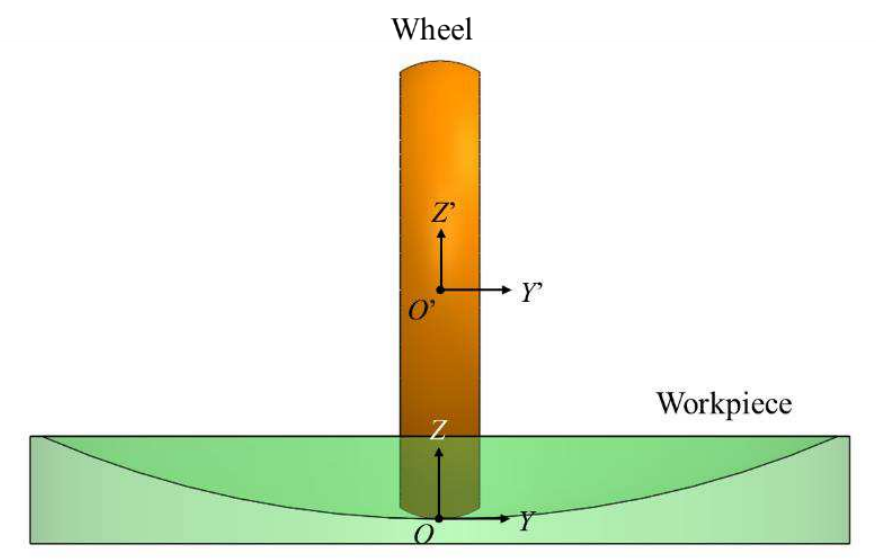

Fig. 4 Coordinate systems for the grinding of the aspheric surface 


$$
\boldsymbol{B}=\left[\begin{array}{c}
X_{s} \\
Y_{s} \\
Z_{s}
\end{array}\right]
$$

In the initial grinding state, the $Z$ axis of the workpiece coordinate system coincides the $Z$ axis of the wheel coordinate system, and the grinding point locates at the point $O$. The translation vector in this state is $\boldsymbol{B}_{0}=\left[\begin{array}{lll}0 & 0 & R\end{array}\right]^{T}$.

For parallel grinding, the wheel moves along the $Y$ and $Z$ axes, and the velocity directions of the grinding wheel and the workpiece are parallel at the grinding point, as shown in Fig. 5 (a). Therefore, $X_{s}$ in vector $\boldsymbol{B}$ remains zero. For cross grinding, the wheel moves along the $X$ and $Z$ axes, and the velocity directions of the wheel and the workpiece are perpendicular at the grinding point, as shown in Fig. 5 (b). As a result, $Y_{s}$ remains zero during grinding.

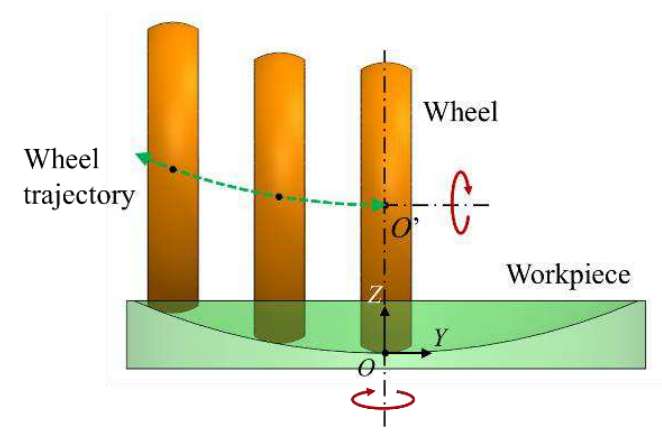

(a) parallel grinding

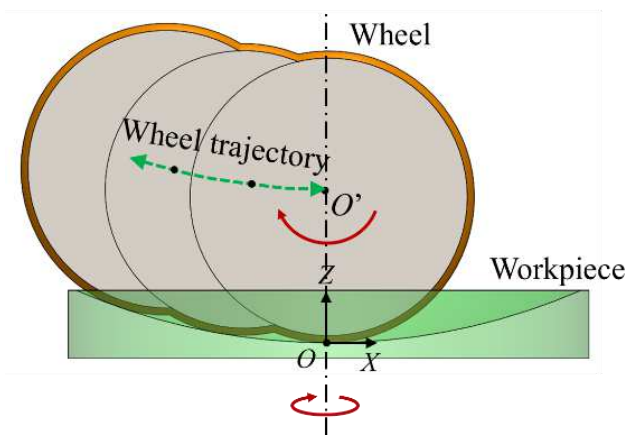

(b) cross grinding

Fig. 5 Parallel grinding and cross grinding of aspherical surfaces using arc grinding wheels

The grinding point is the intersection point of the workpiece and the wheel surfaces. Combining Eqs. (4)-(6) results in 


$$
\left[\begin{array}{c}
h \cos \theta \\
h \sin \theta \\
\frac{c h^{2}}{1+\sqrt{1-(1+k) c^{2} h^{2}}}
\end{array}\right]=\left[\begin{array}{c}
\left(a+r \cos \gamma^{\prime}\right) \cos \theta^{\prime} \\
r \sin \gamma^{\prime} \\
\left(a+r \cos \gamma^{\prime}\right) \sin \theta^{\prime}
\end{array}\right]+\left[\begin{array}{c}
X_{s} \\
Y_{s} \\
Z_{s}
\end{array}\right]
$$

In addition, the workpiece surface is tangent to the wheel surface at the grinding point during the grinding process. Therefore, the normals of the workpiece and the wheel surfaces are collinear at the grinding point. The normal vector at the point $P(h, \theta)$ on the aspherical surface can be expressed as

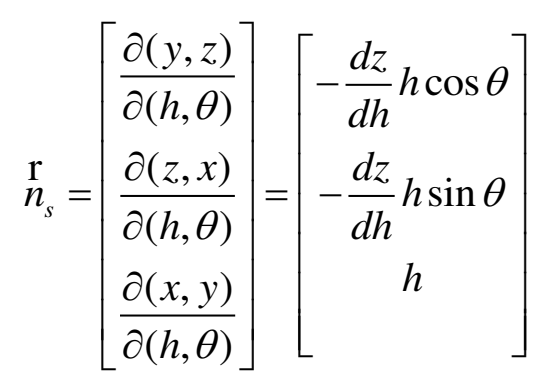

where

$$
\frac{d z}{d h}=z^{\prime}(h)=\frac{c h}{1+\sqrt{1-(k+1) c^{2} h^{2}}}\left(2+\frac{(k+1) c^{2} h^{2}}{\left(1+\sqrt{1-(k+1) c^{2} h^{2}}\right) \sqrt{1-(k+1) c^{2} h^{2}}}\right)
$$

Similarly, the normal vector at a point $P^{\prime}\left(\gamma^{\prime}, \theta^{\prime}\right)$ on the grinding wheel can be written as

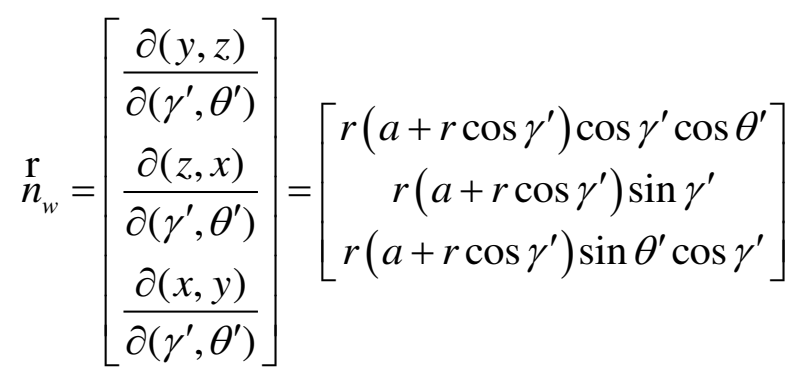

The normals of the workpiece and the wheel surfaces at the grinding point are collinear, so the following equations can be obtained 


$$
\begin{aligned}
\frac{-\frac{d z}{d h} h \cos \theta}{r\left(a+r \cos \gamma^{\prime}\right) \cos \gamma^{\prime} \cos \theta^{\prime}} & =\frac{-\frac{d z}{d h} h \sin \theta}{r\left(a+r \cos \gamma^{\prime}\right) \sin \gamma^{\prime}} \\
& =\frac{h}{r\left(a+r \cos \gamma^{\prime}\right) \sin \theta^{\prime} \cos \gamma^{\prime}}
\end{aligned}
$$

The coordinates of the grinding point and corresponding machining path $f\left(X_{s}, Z_{s}\right)$ or $f\left(Y_{s}, Z_{s}\right)$ can be obtained by solving Eqs. (8) and (12).

The relationship between the coordinates of the grinding point and the trajectory of the grinding wheel can be expressed as

$$
\left[\begin{array}{c}
h \cos \theta \\
h \sin \theta \\
z(h)
\end{array}\right]=\left[\begin{array}{c}
\left(a+r \cos \gamma^{\prime}\right) \cos \theta^{\prime} \\
r \sin \gamma^{\prime} \\
\left(a+r \cos \gamma^{\prime}\right) \sin \theta^{\prime}
\end{array}\right]+\left[\begin{array}{c}
X_{s} \\
Y_{s} \\
Z_{s}
\end{array}\right]
$$

If the trajectory of the grinding wheel relative to the workpiece is known, the expression of $z(h)$ can be obtained by solving Eqs. (12) and (13).

\section{The influence of wheel setting error on workpiece form error}

The influence of the wheel setting error on the workpiece geometry can be analyzed using the generation model of aspherical surface established above. It is assumed that the grinding wheel moves from the center of the workpiece to the outside during grinding. The aspheric surface is a long ellipsoid with $c$ of $1 / 3600$ and $k$ of -0.2 . The wheel is an arc parallel wheel with $R$ of $175 \mathrm{~mm}$ and $r$ of $30 \mathrm{~mm}$.

\subsection{Wheel setting error in the feed direction}

If the wheel setting error is in the outward feed direction (see Fig. 6(a)), the surface profile of the workpiece after grinding can be expressed by the following piecewise function 


$$
z_{1}(h)=\left\{\begin{array}{c}
\frac{c(h-\Delta h)^{2}}{1+\sqrt{1-(k+1) c^{2}(h-\Delta h)^{2}}}, h \geq h_{1} \\
\frac{c_{s}(h-\Delta h)^{2}}{1+\sqrt{1-c_{s}^{2}(h-\Delta h)^{2}}}, h<h_{1}
\end{array}\right.
$$

where $\Delta h$ is the wheel setting error along the feed direction. The value of $h_{1}$ can be determined by the continuity of piecewise function. $h_{1} \approx \Delta h$ when $\Delta h=1 / c_{s}$. $c_{s}=1 / r$ and $1 / R$, respectively, if parallel grinding and cross grinding are performed using the arc parallel wheel.

Fig. 6 (b) compares the workpiece profiles with and without wheel setting error. When the setting error is along the outward feed direction, the workpiece profile is composed of a circular arc and an elliptic curve. It can be seen from Fig. 7 that the workpiece form error is negative and decreased linearly with $h$ in the region $h \geq h_{1}$. The form error at 400 $\mathrm{mm}$ induced by the wheel setting error of $0.4 \mathrm{~mm}$ is $-0.0446 \mathrm{~mm}$ during parallel grinding.

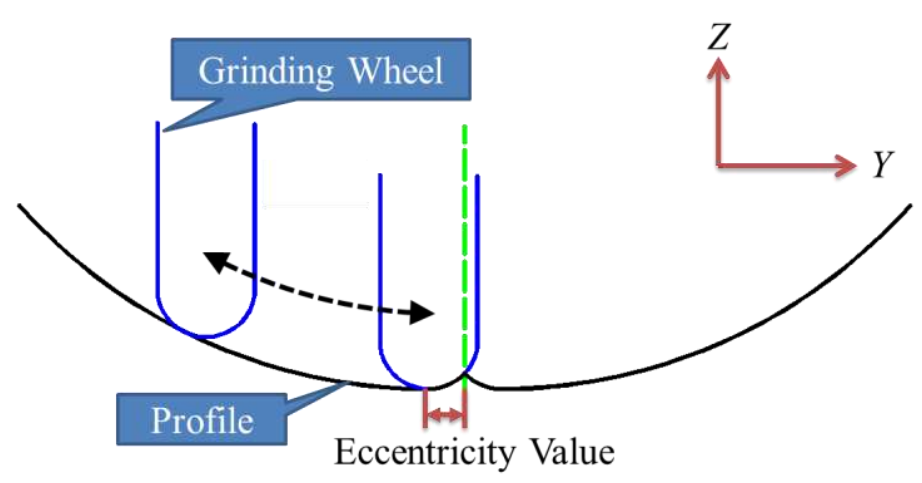

(a) Schematic diagram

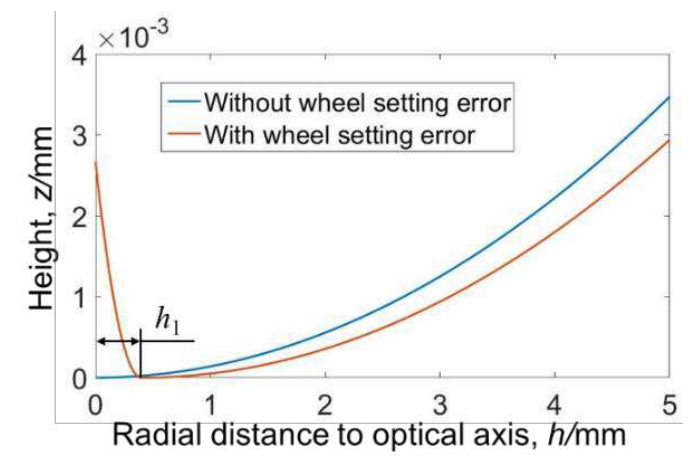


(b) Simulation results

Fig. 6 The influence of the wheel setting error along the positive feed direction on the workpiece profile during parallel grinding $(\Delta h=0.4 \mathrm{~mm})$

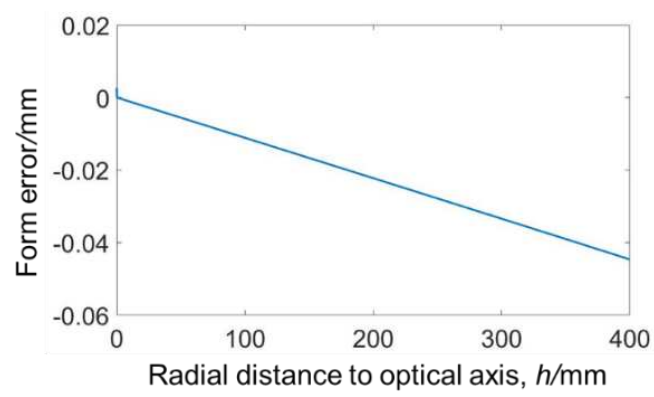

Fig. 7 The evolution of the workpiece form error with the radial distance to the optical axis the for

$$
\Delta h=0.4 \mathrm{~mm}
$$

For the inward tool setting error (see Fig. 8 (a)), the surface profile of the workpiece after parallel grinding can be expressed by the following piecewise function

$$
z_{1}(h)= \begin{cases}\frac{c(-h-\Delta h)^{2}}{1+\sqrt{1-(k+1) c^{2}(-h-\Delta h)^{2}}}, \quad h<h_{2} \\ \frac{c_{s}(-h-\Delta h)^{2}}{1+\sqrt{1-c_{s}^{2}(-h-\Delta h)^{2}}}, \quad h_{2} \leq h<h_{3} \\ \frac{c(h-\Delta h)^{2}}{1+\sqrt{1-(k+1) c^{2}(h-\Delta h)^{2}}}, \quad h \geq h_{3}\end{cases}
$$

The values of $h_{2}$ and $h_{3}$ can be obtained from the continuity of the curve. $h_{2} \approx \Delta h$ when $\Delta h=1 / c_{s}$. The profile of the workpiece is composed of two elliptic curves and one circular arc, as shown in Fig. 8. Fig. 9 demonstrates that the form error increases linearly with $h$ in the region $h \geq h_{3}$. The tool setting error of $\Delta h=-0.4 \mathrm{~mm}$ leads to a form error of $0.0447 \mathrm{~mm}$ at the radius of $400 \mathrm{~mm}$. Its absolute value is close to that induced by $\Delta h=0.4 \mathrm{~mm}$. Therefore, the direction and magnitude of the wheel setting error determines the shape and magnitude of the form error profile, respectively. 


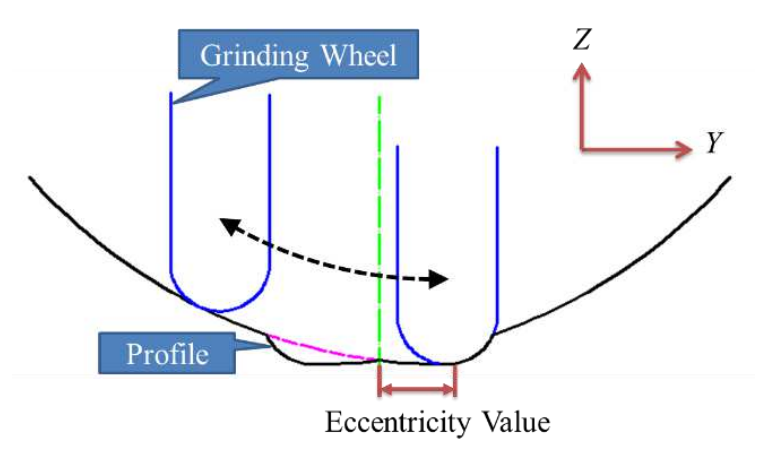

(a) Schematic diagram

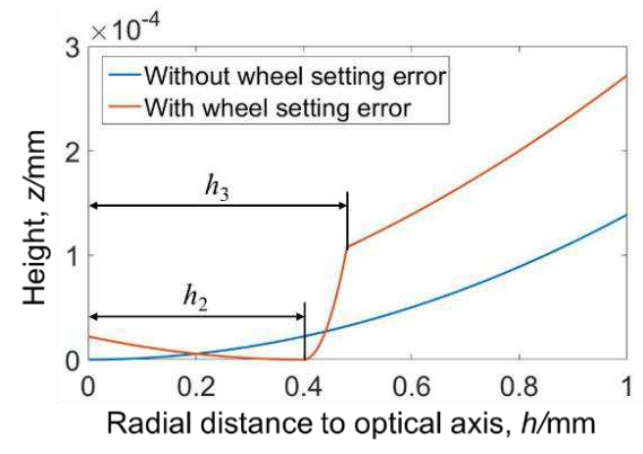

(b) Simulation results

Fig. 8 The influence of the inward wheel setting error on the workpiece profile during parallel grinding $(\Delta h=-0.4 \mathrm{~mm})$

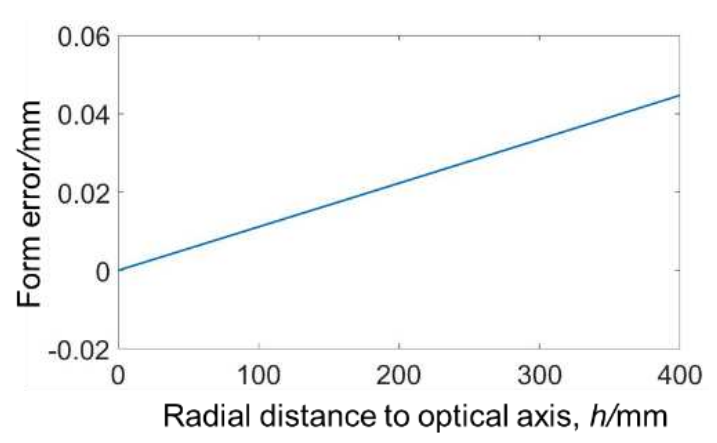

Fig. 9 The evolution of the workpiece form error with the radial distance to the optical axis during parallel grinding $(\Delta h=-0.4 \mathrm{~mm})$

The wheel setting error determines the slope between the form error and $h$. As shown in Fig. 10, the absolute value of the slope increases linearly with the wheel setting error in the feed direction. This relationship can be used to determine the value of the wheel setting error. 


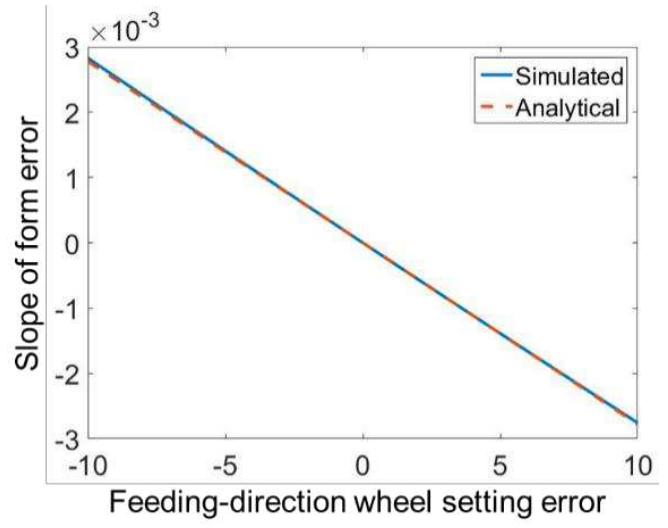

Fig. 10 The slope of workpiece form error as a function of the wheel setting error in the feed direction

The relationship between the slope of the form error and the wheel setting error can also be obtained by theoretical analysis. When $h \geq h_{1}$ (or $h \geq h_{3}$ ) and $\Delta h$ is small, the form error can be expressed by Taylor expansion, i.e.,

$$
e_{z}=z_{1}(h)-z(h) \approx-z^{\prime}(h) \Delta h
$$

where $z_{1}$ and $z$ are the actual and ideal profiles, respectively. $e_{z}$ for quadratic aspheric surface is

$$
e_{z}=-\frac{c h}{1+\sqrt{1-(k+1) c^{2} h^{2}}}\left(2+\frac{(k+1) c^{2} h^{2}}{\left(1+\sqrt{1-(k+1) c^{2} h^{2}}\right) \sqrt{1-(k+1) c^{2} h^{2}}}\right) \Delta h
$$

$h=R_{0}$ and $(k+1) c^{2} h^{2}=1$ because $h \leq 400 \mathrm{~mm}$ and $R_{0}=3600 \mathrm{~mm}$ in this study. Eq.

(17) can then be reduced to $e_{z} \approx-c h \Delta h$. Therefore, the form error is a bilinear function of $h$ and $\Delta h$. This is consistent with the simulation results shown in Fig. 7, Fig. 9 and Fig. 10. Eq. (17) indicates that the slope between $e_{z}$ and $h$ is $-c h$, which is close to the simulated slope, as indicated by Fig. 10. $e_{z}$ can be obtained by numerically solving Eqs. (14) or (15) when $h=R_{0}$ is not satisfied.

\subsection{Lateral wheel setting error}

The form error of the workpiece in the region of $h \geq \Delta l$ caused by the lateral wheel setting 
error $\Delta l$ can only be solved by numerical methods. $X_{s}$ equals $\Delta l$ for parallel grinding, while $Y_{s}$ and $Z_{s}$ follows the trajectory without wheel setting error. For cross grinding, $Y_{s}$ is equal to $\Delta l$, and $X_{s}$ and $Z_{s}$ follows the trajectory without wheel setting error. Then, the surface profile and form error of the workpiece in the region $h \geq \Delta l$ can be obtained by numerically solving Eq. (13).

The surface profile of the workpiece in the region of $h<\Delta l$ is a circular arc with the expression of

$$
z_{1}(h)=\frac{c_{s}(h-\Delta l)^{2}}{1+\sqrt{1-c_{s}^{2}(h-\Delta l)^{2}}}
$$

$c_{s}$ equals $1 / R$ and $1 / r$, respectively, for parallel grinding and cross grinding using arc grinding wheels.

The influence of the lateral wheel setting error on the surface profile and form error is demonstrated in Fig. 11. The maximum form error is located at the center of the aspherical surface. It is smaller than $0.1 \mu \mathrm{m}$ because $c_{s}$ is very small in this study. The form error decreases with $h$ and remains nearly constant in the region of $h \geq \Delta l$.

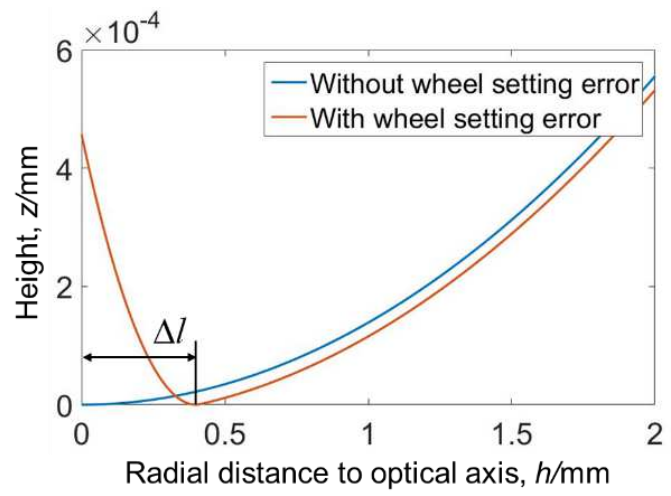

(a) Profiles

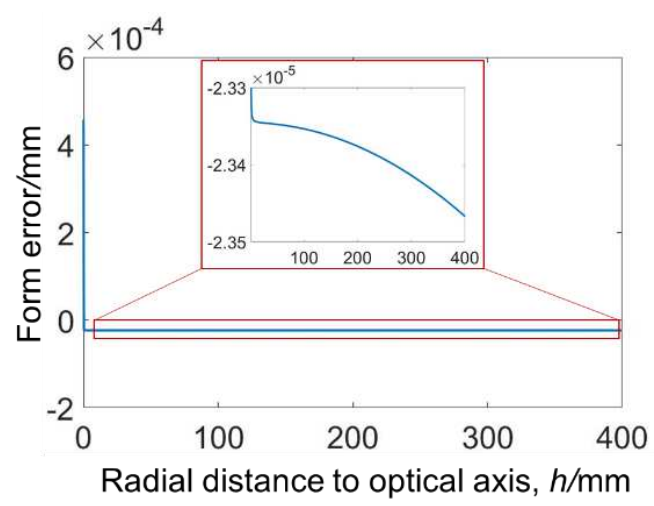

(b) Form error

Fig. 11 The influence of lateral wheel setting error on the workpiece profile for parallel grinding

$$
(\Delta l=0.4 \mathrm{~mm})
$$

Since the $c_{s}$ value for cross grinding is much greater than that for parallel grinding, the 
maximum form error is also much greater than that for parallel grinding, as indicated by in Fig. 11 and Fig. 12. The form error of the workpiece in the region of $h \geq \Delta l$ is very small and nearly constant, which is similar to parallel grinding.

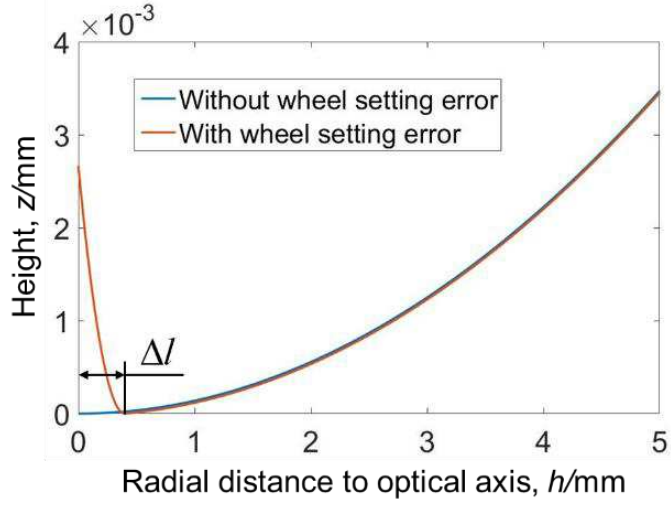

(a) surface profiles

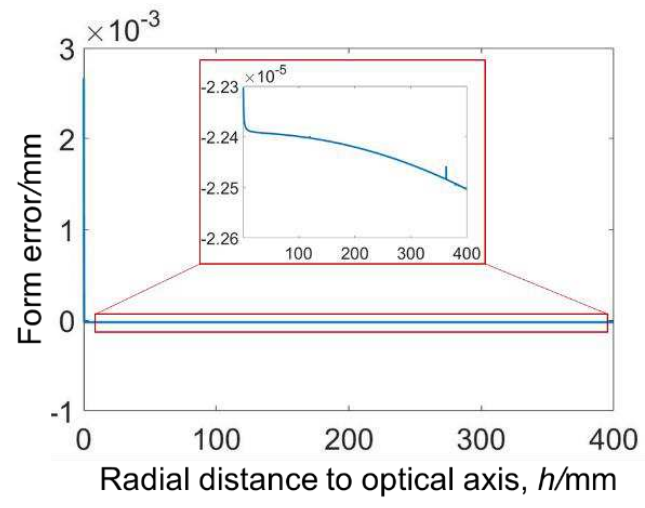

(b) form error

Fig. 12 The workpiece profiles and form error as a function of the lateral wheel setting error

$$
\text { during cross grinding }(\Delta l=0.4 \mathrm{~mm})
$$

In summary, the feed-direction wheel setting error results in a significantly higher form error than the lateral wheel setting error during the grinding of large-aperture aspherical surfaces. The form error induced by the feed-direction wheel setting error reaches its maximum at the rim of the workpiece. It is bilinear with the wheel setting error and the distance to the optical axis. The form error of the workpiece caused by the lateral wheel setting error reaches its maximum value at the center of the workpiece. The form error in the central region is much more sensitive to the wheel setting error in the tangential direction of the grinding wheel than that in the axial direction.

\section{Error compensation and grinding tests}

\subsection{Error compensation}

Because the form error is much more sensitive to the wheel setting error along the feed direction than that along the lateral direction, only the feed-direction wheel setting error was considered during the grinding of large-aperture aspheric surfaces. The value of the wheel setting error is determined by the slope between the form error and $h$. 
The dash line in Fig. 13 is the measured error curve of the workpiece after wheel changing. It consists of two straight lines forming the $\mathrm{V}$ shape, which is in good agreement with the theoretical error curve induced by the wheel setting error of $\Delta h$ $=2.89 \mathrm{~mm}$, i.e., the dotted line in Fig. 13. This indicates that wheel changing led to significant wheel setting errors. The wheel setting error determined by the above method was used for error compensation during the subsequent grinding process.

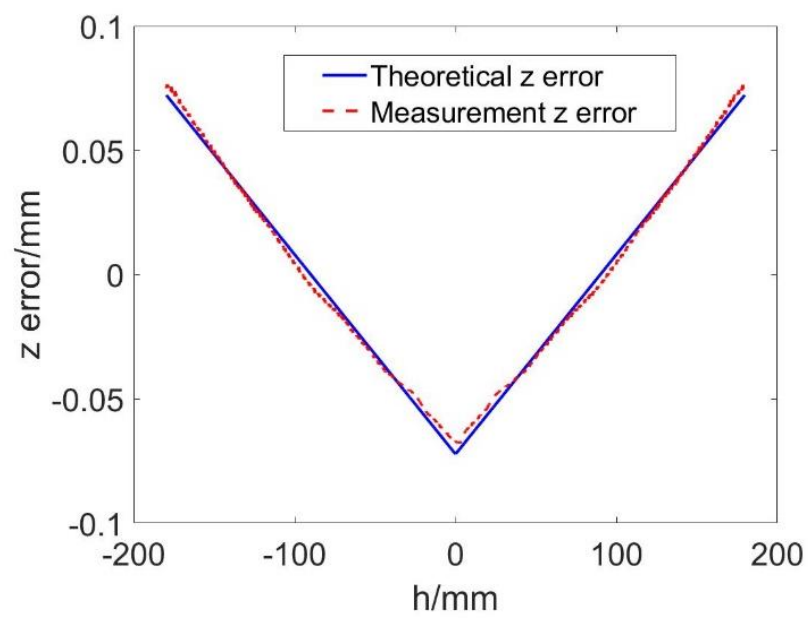

Fig. 13 Theoretical and measured error curves caused by the wheel setting error

After correcting the wheel setting error, the error compensation method shown in Fig. 14 was used to further reduce the machining error. First, a coordinate measuring machine (CMM) (Leitz Reference HP, Hexagon, China) was used to measure the profile of the aspherical generatrix, and the error curve $E$ was obtained by subtracting the theoretical curve from it. The low-pass filtering of $E$ was then performed to eliminate the effects of random machining errors, which resulted in the filtered error curve $E_{f}$. The theoretical compensation curve $\Delta_{t}$ is the opposite of the filtered error curve $E_{f}$. A compensation factor $f$ was introduced to obtain the actual compensation curve $\Delta_{a}$. Finally, the current grinding curve $C_{a f t e r}$ was obtained by adding $\Delta_{a}$ and the former grinding curve $C_{\text {before }}$ (i.e., the envelope of the outer circumference of the grinding wheel) together. 


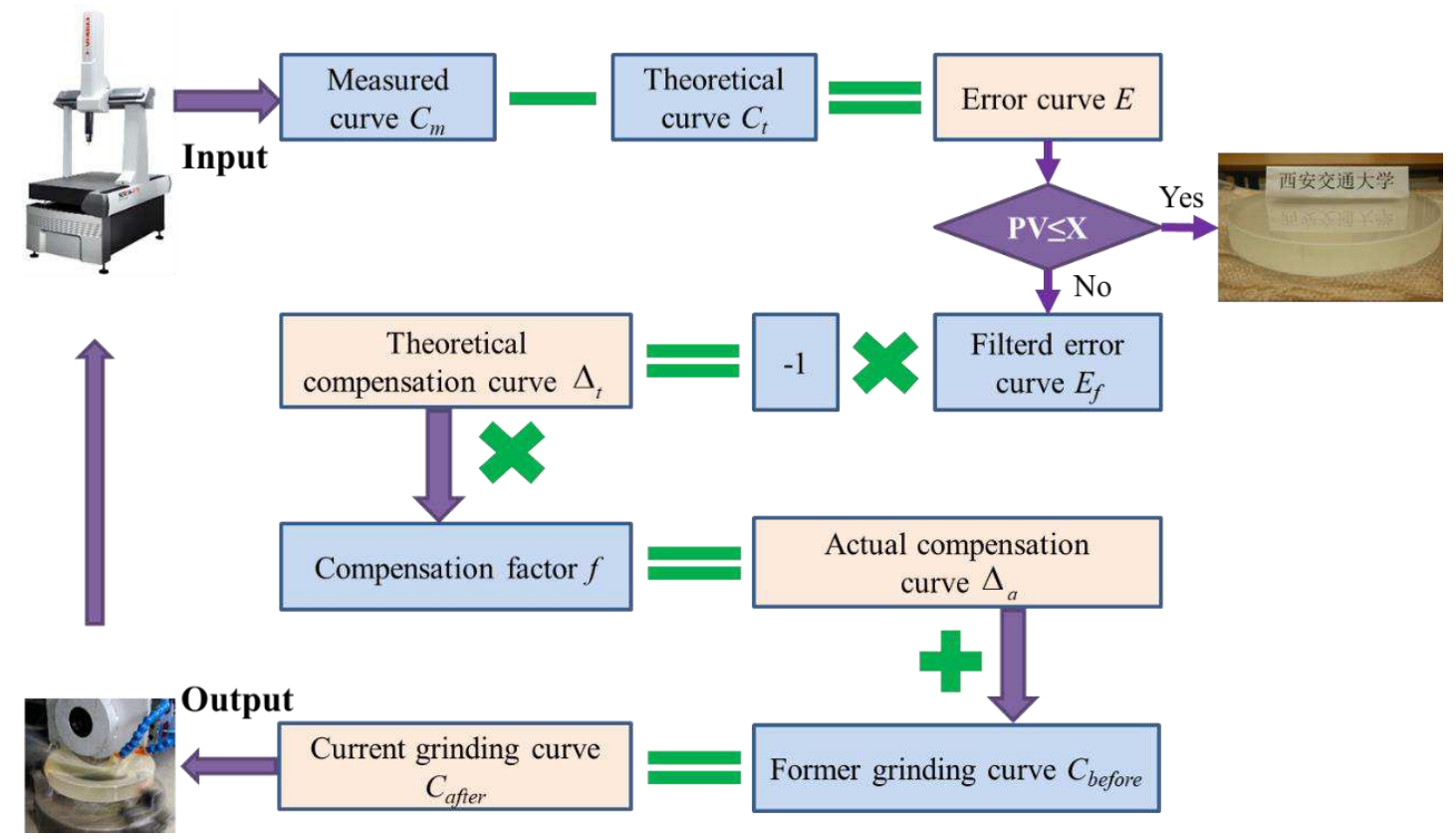

Fig. 14 Error compensation during grinding

The trajectory of the wheel center, i.e., the grinding path $f\left(X_{s}, Z_{s}\right)$ or $f\left(Y_{s}, Z_{s}\right)$, was obtained by solving Eqs. (8) and (12) using $C_{a f t e r}$ as input. The grinding path was then used to machine the workpiece, and the machined workpiece was measured by the CMM. If the PV value of the form error was out of the tolerance, a compensation grinding process was performed based on the measured error curve until the form error met the requirement.

The tilt of the error curve was adjusted before calculating the form error to eliminate the influence of the workpiece clamping error. An axis of symmetry exists on the machined surface because it is rotating during the machining process. The equation of this symmetry axis is assumed to be $z=k x+b$. The slope $k$ and the intercept $b$ are varied at certain intervals to determine their optimal values. For each $k$ and $b$, the measurement points $P_{l}\left(h_{1}, z_{1}\right)$ on the left side of the symmetry axis was mirrored to the right side to obtain the mirror points $P_{l}^{\prime}\left(h_{1}^{\prime}, z_{1}^{\prime}\right)$. The measurement points $P_{r}\left(h_{2}, z_{2}\right)$ on the right side of the symmetry axis were interpolated to obtain the interpolation points 
$P_{r}^{\prime}\left(h_{1}^{\prime}, z_{2}^{\prime}\right)$. Then, the Z-direction difference $e_{z}\left(h_{1}^{\prime}\right)$ between each mirror point and its corresponding interpolation point was calculated. The $k$ and $b$ resulting in the smallest root mean square of $e_{z}\left(h_{1}^{\prime}\right)$ define the optimal symmetry axis. Finally, the error curve was rotated to make the symmetry axis vertical. The error curves before and after tilt correction are shown in Fig. 15 (a) and (b), respectively.

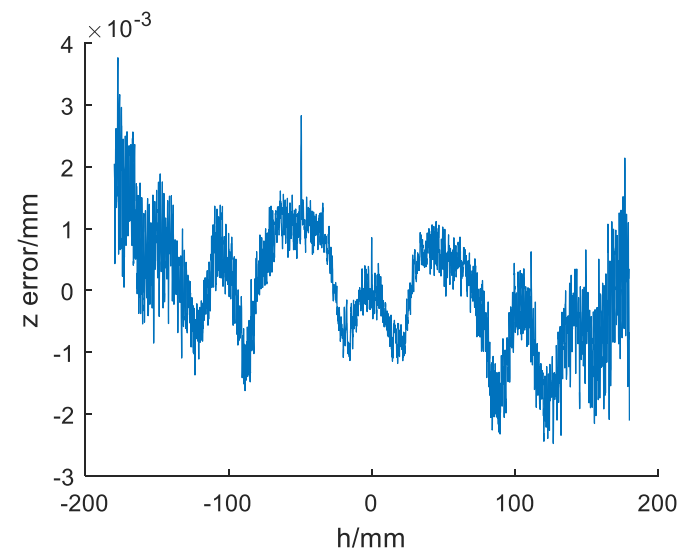

(a) Before correction

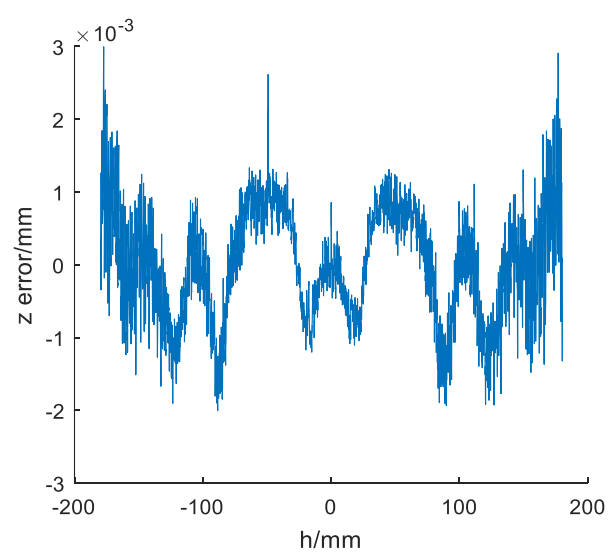

(b) After correction

Fig. 15 Error curves of workpiece generatrix before and after tilt correction

An error compensation factor of 1:1 is appropriate for rough grinding. However, Fig. 16 indicates that a compensation factor of 1:1 led to obvious over compensation when the error is small (e.g., within $10 \mu \mathrm{m})$. As a result, the locations of the peaks before compensation corresponded well to the valleys after compensation. The PV form error of $6.9 \mu \mathrm{m}$ after compensation was close to that before compensation, i.e., $7.9 \mu \mathrm{m}$. Therefore, the compensation factor of 0.5 was adopted in the fine grinding stage. As a result, the PV form error was significantly reduced to $3.3 \mu \mathrm{m}$. 


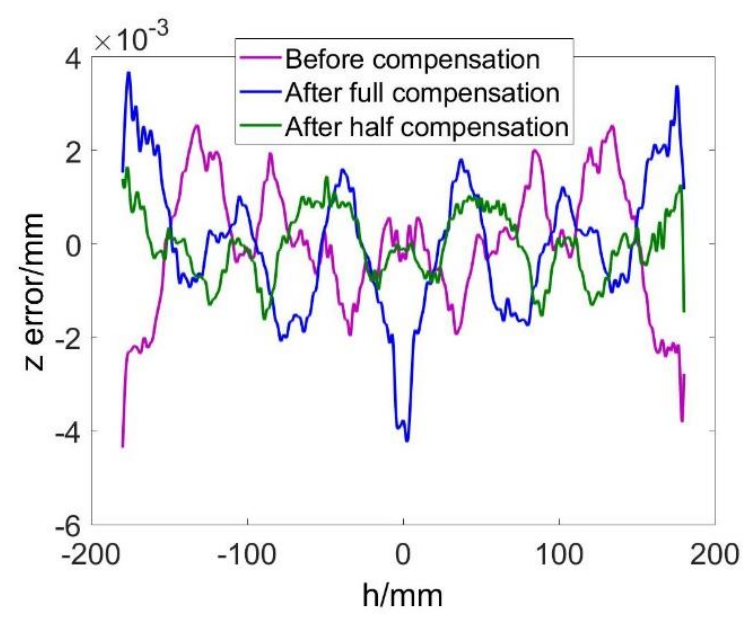

Fig. 16 Error curves of workpiece generatrix before and after compensation

\subsection{Grinding tests}

The parallel grinding tests of $\mathrm{K} 9$ glass with a diameter of $\Phi 400 \mathrm{~mm}$ were carried out on the CM1500 large grinding machine (see Fig. 17). The maximum machinable diameter of the machine tool is $\geq \Phi 1500 \mathrm{~mm}$. the $X$ and $Z$ axes has the resolution of 10 $\mathrm{nm}$ and strokes of $1800 \mathrm{~mm}$ and $400 \mathrm{~mm}$, respectively. The high-stiffness hydrostatic spindle with the runout of $\leq 0.2 \mu \mathrm{m}$ is used to achieve high machining precision. The geometry of the workpiece and the grinding wheel are consistent with the simulation. The grinding process consists of three stages, i.e., rough grinding, semi-finishing grinding and fine grinding.

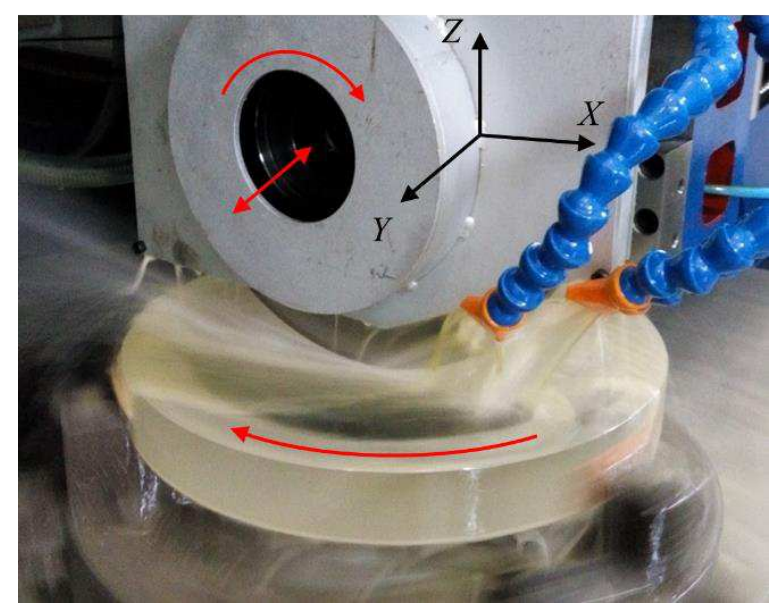

Fig. 17 Grinding of a $\Phi 400 \mathrm{~mm}$ K9 glass blank on the CM1500 large grinding machine

The process parameters of all grinding stages are listed in Table 1. A D151 metal- 
bonded diamond grinding wheel with the grain dimension of $127-160 \mu \mathrm{m}$ was used in the rough grinding stage to ensure high material removal rate. A D46 metal-bonded diamond wheel with grain dimension of $40-50 \mu \mathrm{m}$ was used in the semi-finishing stage. A shallower grinding depth and a lower feed rate were adopted in this stage, which can reduce the form error of the aspherical workpiece to less than $5 \mu \mathrm{m}$. A D15A resinbonded diamond wheel with the grain dimension of 10-15 $\mu \mathrm{m}$ was used in the fine grinding stage to reduce the surface roughness and subsurface damage depth. The form error of $3.4 \mu \mathrm{m}$ PV was achieved after error compensation using the process parameters listed in Table 1, as demonstrated in Fig. 18.

Table 1 Process parameters

\begin{tabular}{|c|c|c|c|c|c|}
\hline $\begin{array}{c}\text { Grinding } \\
\text { stage }\end{array}$ & $\begin{array}{c}\text { Grit } \\
\text { designation }\end{array}$ & $\begin{array}{c}\text { Wheel speed } \\
(\mathrm{r} / \mathrm{min})\end{array}$ & $\begin{array}{c}\text { Workpiece } \\
\text { speed (r/min) }\end{array}$ & $\begin{array}{c}\text { Grinding } \\
\text { depth }(\mathrm{mm})\end{array}$ & $\begin{array}{l}\text { Feed rate } \\
(\mathrm{mm} / \mathrm{min})\end{array}$ \\
\hline Rough & D151 & 2000 & 10 & 0.5 & $10 \sim 30$ \\
\hline Semi-finish & D46 & 2300 & 15 & $0.05 \sim 0.1$ & $10 \sim 20$ \\
\hline Fine & D15A & 2500 & 15 & 0.005 & $2 \sim 5$ \\
\hline & 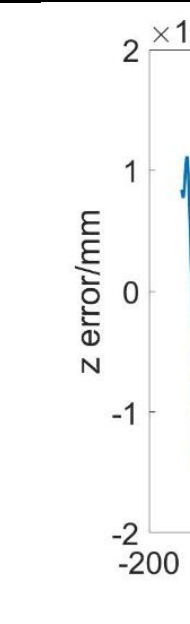 & $\begin{array}{l}\sqrt{ } \\
-100\end{array}$ & $\int \sqrt{1}$ & $\underbrace{}_{200}$ & \\
\hline
\end{tabular}

Fig. 18 The error curve of an aspherical surface after grinding. It is worth noting that the surface roughness was removed by a low pass filter

\section{Conclusions}

In this study, the analytical form error models of aspherical optical elements induced 
by wheel setting errors are established for both parallel grinding and cross grinding. It is found that the feed-direction wheel setting error results in a significantly higher form error than the lateral wheel setting error during the grinding of large-diameter aspherical surfaces. The maximum form error induced by the feed-direction wheel setting error is located at the rim of the workpiece. It is bilinear with the wheel setting error and the distance to the optical axis. The form error of the workpiece caused by the lateral wheel setting error reaches its maximum value at the center of the workpiece. The form error in the central region is much more sensitive to the wheel setting error in the tangential direction of the grinding wheel than that in the axial direction.

Based on above investigation, the wheel setting error was determined and used to accurately align the wheel during the grinding tests. An error compensation method considering tilt correction, filtering, and partial compensation was proposed to efficiently reduce the form error. Results show a form error of $3.4 \mu \mathrm{m}$ PV for a $\Phi 400$ mm elliptical K9 glass surface.

\section{Availability of data and materials}

The datasets used and/or analysed during the current study are available from the corresponding author on reasonable request.

\section{Competing interests}

The authors declare that they have no competing interests.

\section{Funding}

This work was supported by the fellowship of China National Postdoctoral Program for Innovative Talents (grant number BX20200268); the Research Project of State Key Laboratory of Mechanical System and Vibration (grant number MSV202103); the National Natural Science Foundation of China (grant number 51720105016); and the 
Higher Education Discipline Innovation Project (grant number B12016).

\section{Authors' contributions}

Changsheng Li was in charge of the theoretical analysis, experiments and manuscript writing. Lin Sun took part in the experimental design and grinding tests. Zhaoxiang Chen and Jianfang Chen participated in measuring the workpiece form error. Qijing Lin, Jianjun Ding and Zhuangde Jiang assisted with the modeling and data analysis. All authors read and approved the final manuscript.

\section{Acknowledgements}

Not applicable.

\section{References}

André, M. L. (1999). The French megajoule laser project (LMJ). Fusion Engineering and Design, 44(1), 43-49.

Bin, L., Jianpu, X., Dongxu, R., Zexiang, Z., \& Zhao, H. (2019). Compensation grinding and independent on-machine measurement of symmetric aspheric mirror. Manufacturing Technology and Machine Tool(2), 129-134.

Campbell, J. H., Hawley-Fedder, R. A., Stolz, C. J., Menapace, J. A., Borden, M. R., Whitman, P. K., ... Feit, M. D. (2004). NIF optical materials and fabrication technologies: an overview. Paper presented at the Lasers and Applications in Science and Engineering.

Chen, F., Yin, S., Huang, H., \& Ohmori, H. (2015). Fabrication of small aspheric moulds using single point inclined axis grinding. Precision Engineering, 39, 107-115. doi:https://doi.org/10.1016/j.precisioneng.2014.06.009

Comley, P., Morantz, P., Shore, P., \& Tonnellier, X. (2011). Grinding metre scale mirror segments for the E-ELT ground based telescope. CIRP Annals-Manufacturing Technology, 60(1), 379-382.

Feng, Z., Di, F., Ruigang, L., Zheng, L., Gao, J., \& Zhang, X. (2008). Fabrication and testing of aspheric silicon carbide mirror. journal of applied optics, 29(6), 1004-1008.

Gray, P., Ciattaglia, E., Dupuy, C., Gago, F., Guisard, S., Marrero, J., .. Wright, A. (2016). E-ELT assembly, integration, and technical commissioning plans. Paper presented at the SPIE 
Astronomical Telescopes + Instrumentation.

Maeng, S., \& Min, S. (2020). Simultaneous geometric error identification of rotary axis and tool setting in an ultra-precision 5-axis machine tool using on-machine measurement. Precision Engineering, 63, 94-104. doi:https://doi.org/10.1016/j.precisioneng.2020.01.007

Martin, H. M., Allen, R. G., Burge, J. H., Dettmann, L. R., Ketelsen, D. A., Miller III, S. M., \& Sasian, J. M. (2003). Fabrication of mirrors for the Magellan Telescopes and the Large Binocular Telescope. Paper presented at the Astronomical Telescopes and Instrumentation.

Parks, R. E., Lam, P., \& Kuhn, W. (1985). The large optical generator: a progress report. Paper presented at the 1985 Albuquerque Conferences on Optics.

Shore, P., Morantz, P., Luo, X., Tonnellier, X., Collins, R., Roberts, A., . . Read, R. (2005). Big OptiX ultra precision grinding/measuring system. Paper presented at the Optical Systems Design 2005.

Shore, P., \& Parr-Burman, P. (2004). Manufacture of large mirrors for ELTs: a fresh perspective. Paper presented at the Optical Systems Design.

Sun, L., Yang, S., Zhao, P., Ding, J., Long, X., \& Jiang, Z. (2017). Optimal design and simulation of the stepped beam of a large-scale ultra-precision optical aspheric machine. International Journal of Nanomanufacturing, 13(3). doi:10.1504/IJNM.2017.10005584

Usuda, T., Ezaki, Y., Kawaguchi, N., Nagae, K., Kato, A., Takaki, J., . . Horiuchi, Y. (2014). Preliminary design study of the TMT telescope structure system: overview. Paper presented at the SPIE Astronomical Telescopes+ Instrumentation.

Wang, G., Li, S., \& Dai, Y. (2004). Design method and accuracy analysis of aspherical optical compound machine tool. journal of mechanical engineering, 15(2), 99-102.

Wang, Y., Zhang, C., He, Y., Tao, L., \& Feng, H. (2018). Development and evaluation of non-contact automatic tool setting method for grinding internal screw threads. The International Journal of Advanced Manufacturing Technology, 98(1), 741-754. doi:10.1007/s00170-018-2258-5

Wei, X., Li, B., Chen, L., Xin, M., Liu, B., \& Jiang, Z. (2018). Tool setting error compensation in large aspherical mirror grinding. The International Journal of Advanced Manufacturing Technology, 94(9), 4093-4103. doi:10.1007/S00170-017-1094-3

West, S., Martin, H., Nagel, R., Young, R., Davison, W., Trebisky, T., . . Hille, B. (1994). Practical design and performance of the stressed-lap polishing tool. Applied Optics, 33(34), 8094-8100. 
Xi, J. P., Zhao, H. Y., Li, B., \& Ren, D. X. (2016). Profile error compensation in cross-grinding mode for large-diameter aspheric mirrors. The International Journal of Advanced Manufacturing Technology, 83(9), 1515-1523. doi:10.1007/s00170-015-7689-7

Xuejun, Z., Yunfeng, Z., Jingchi, Y., \& Zhongyu, Z. (1997). FSGJ 1 Aspheres Automatic Fabrication and on line Testing System. Optics and Precision Engineering, 5(2), 70-76.

Zhang, Z., Li, R., Zheng, L., \& Zhang, X. (2013). Precision Grinding Technology for the Off-axis Aspherical Silicon Carbide Mirror Blank. journal of mechanical engineering, 49(17). doi:10.3901/JME.2013.17.039 
Figures

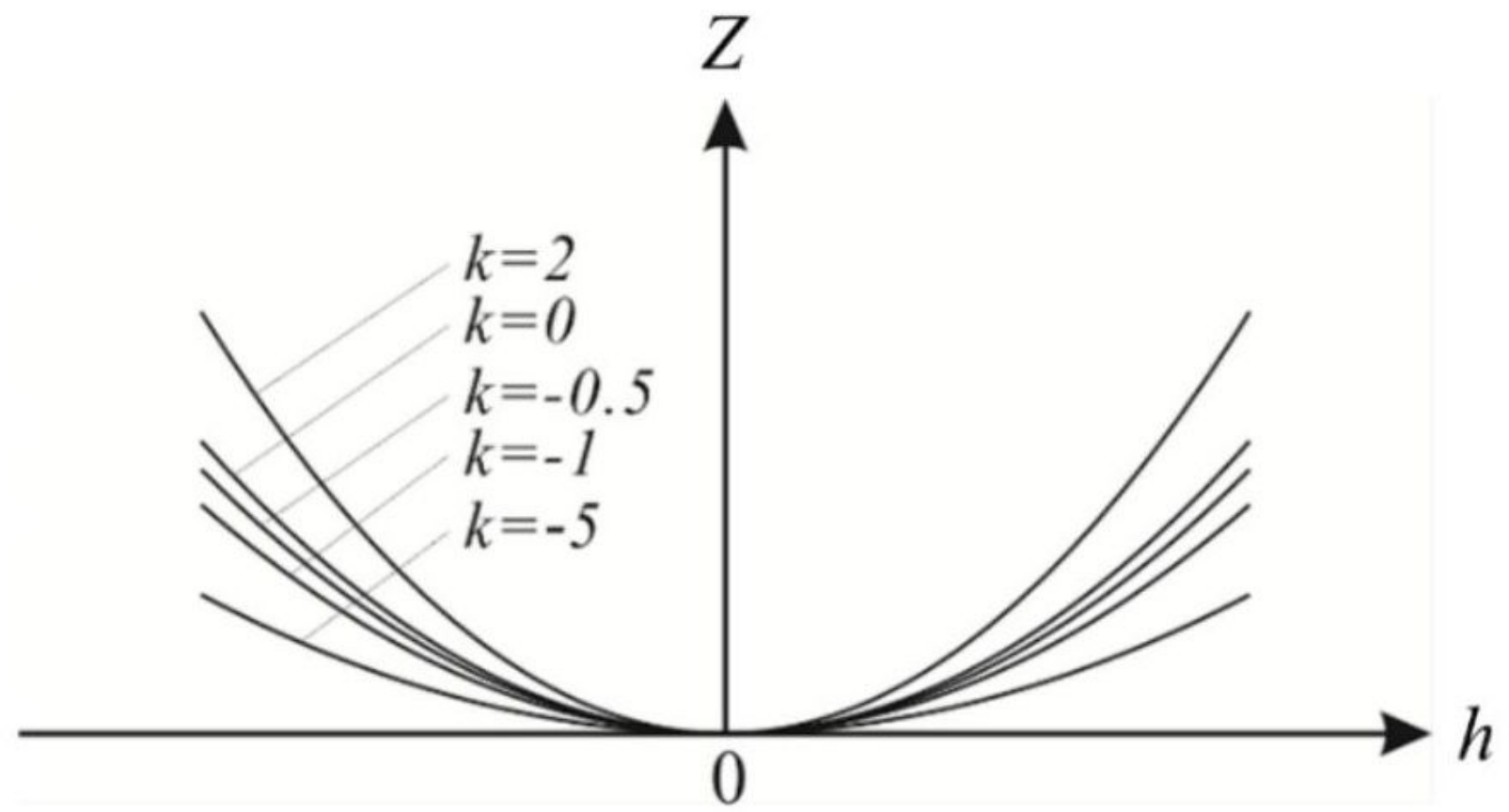

Figure 1

Surfaces corresponding to different conic constants $k$ 


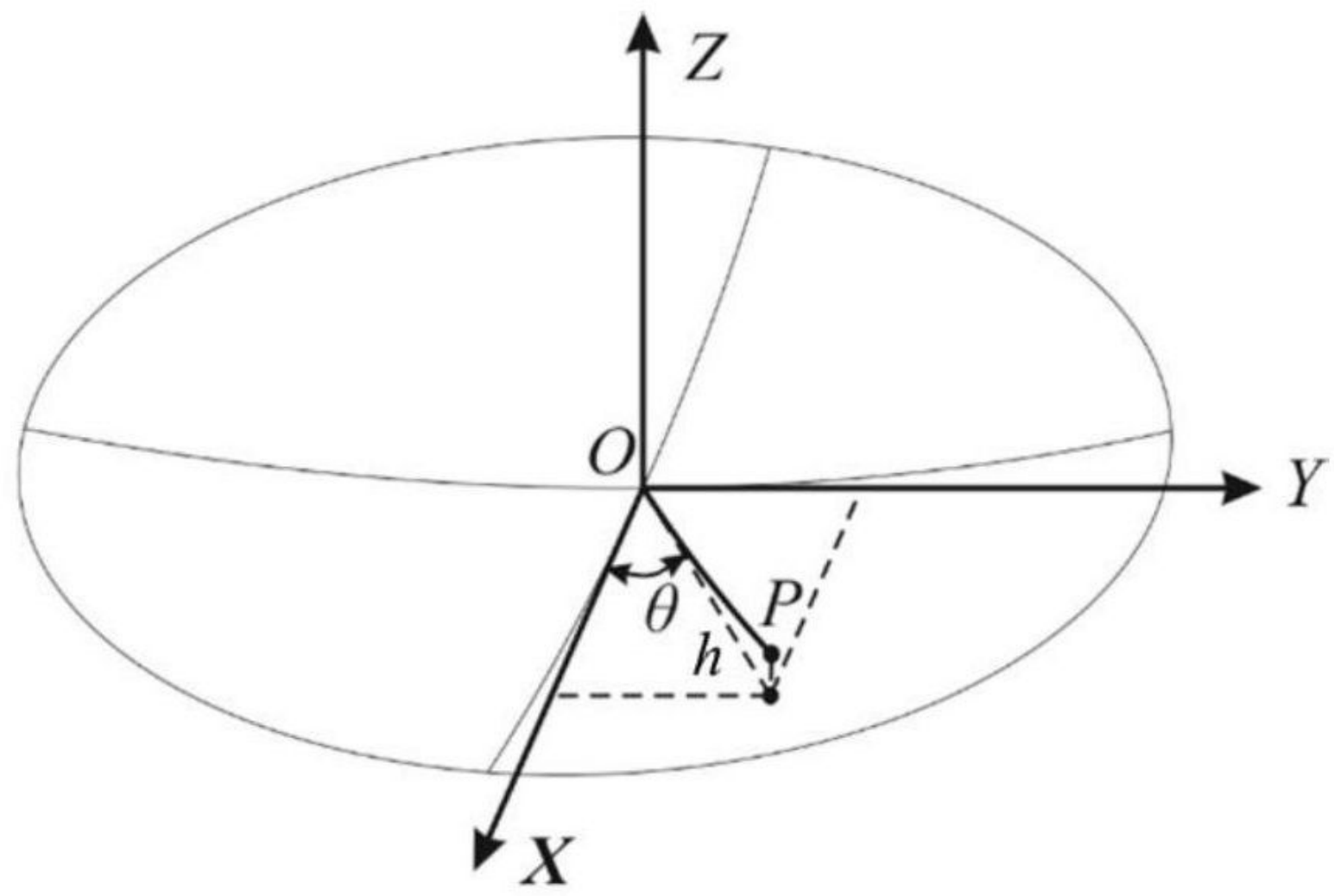

Figure 2

Coordinate system of aspheric workpiece 


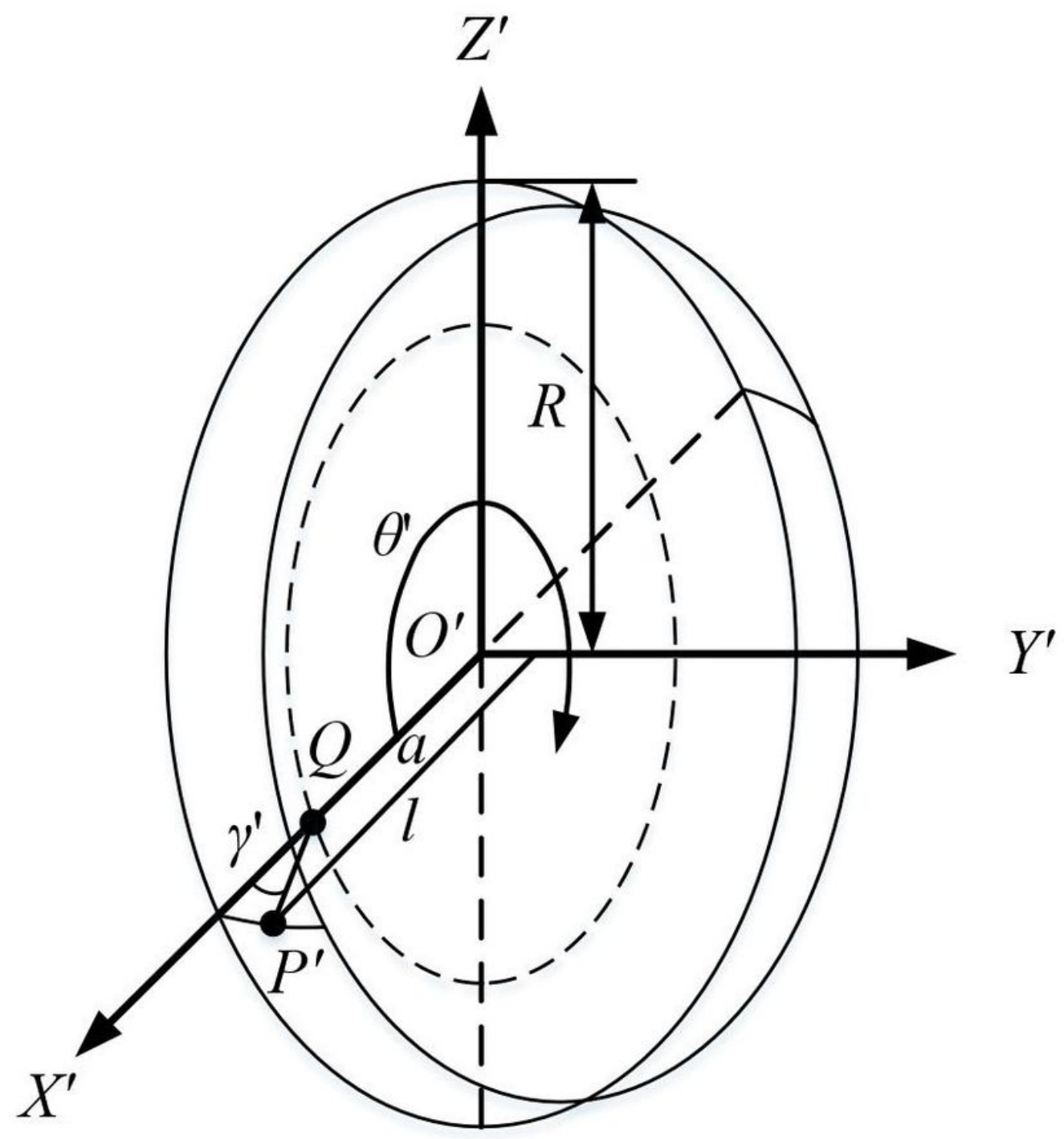

Figure 3

Coordinate system of grinding wheel. Only the region of $Y^{\prime} \geq 0$ is shown because the wheel is symmetrical about the $X^{\prime} O^{\prime} Z$ ' plane 


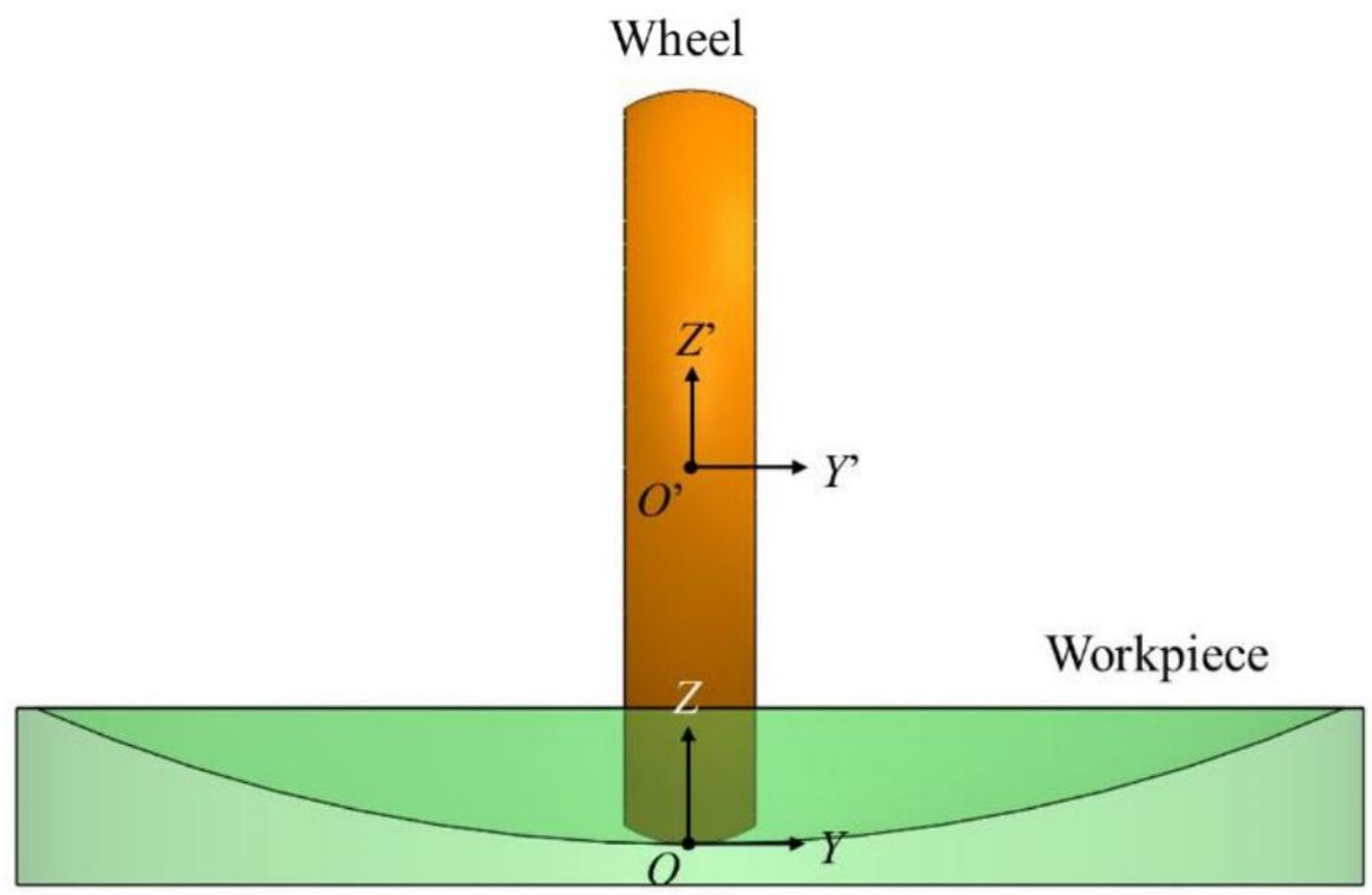

\section{Figure 4}

Coordinate systems for the grinding of the aspheric surface

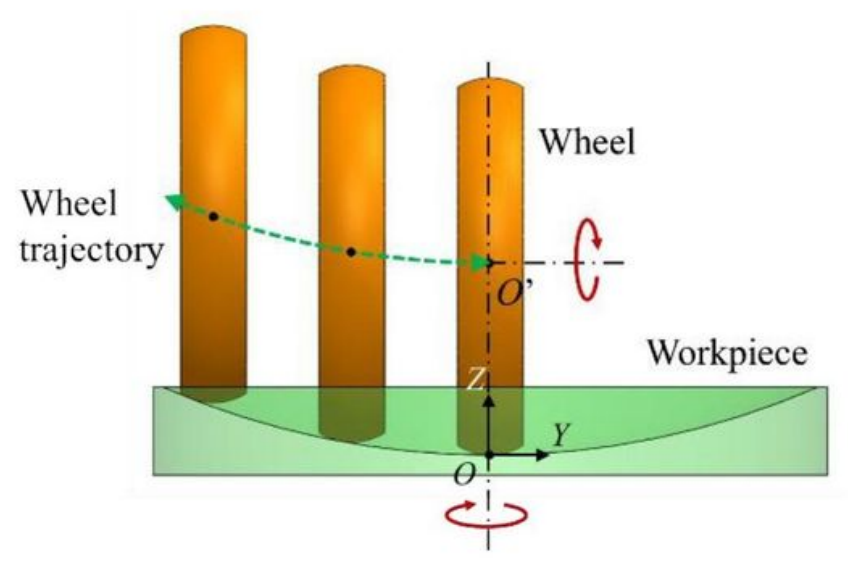

(a) parallel grinding

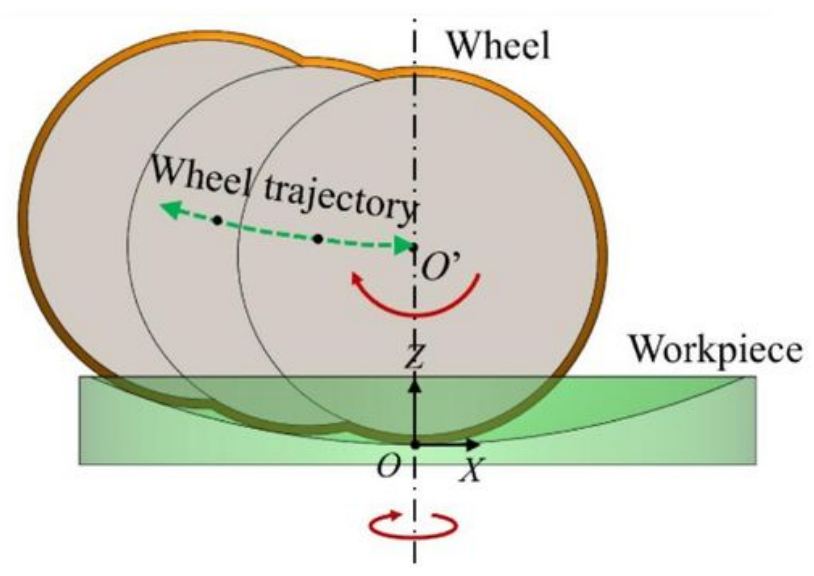

(b) cross grinding

\section{Figure 5}

Parallel grinding and cross grinding of aspherical surfaces using arc grinding wheels 


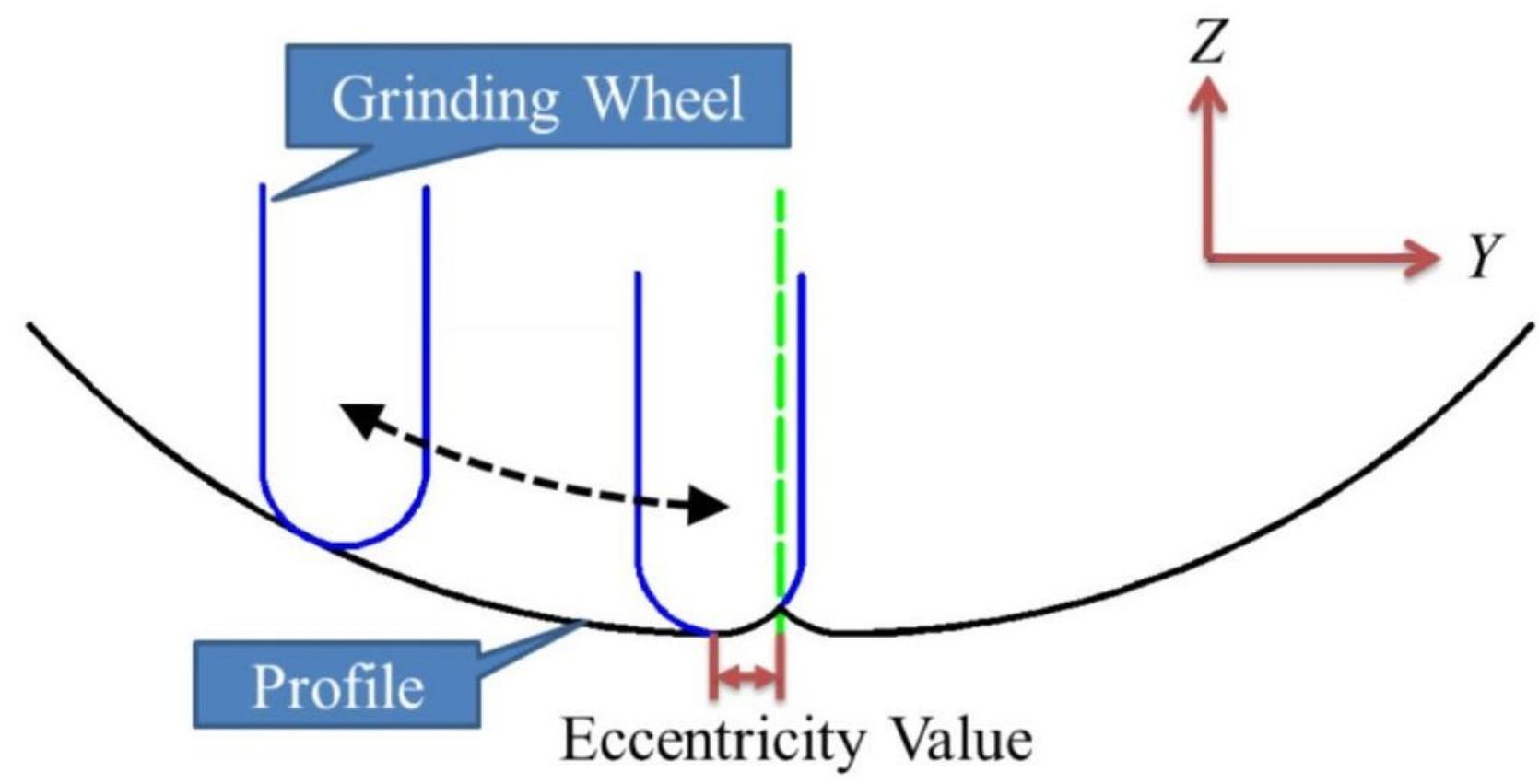

(a) Schematic diagram

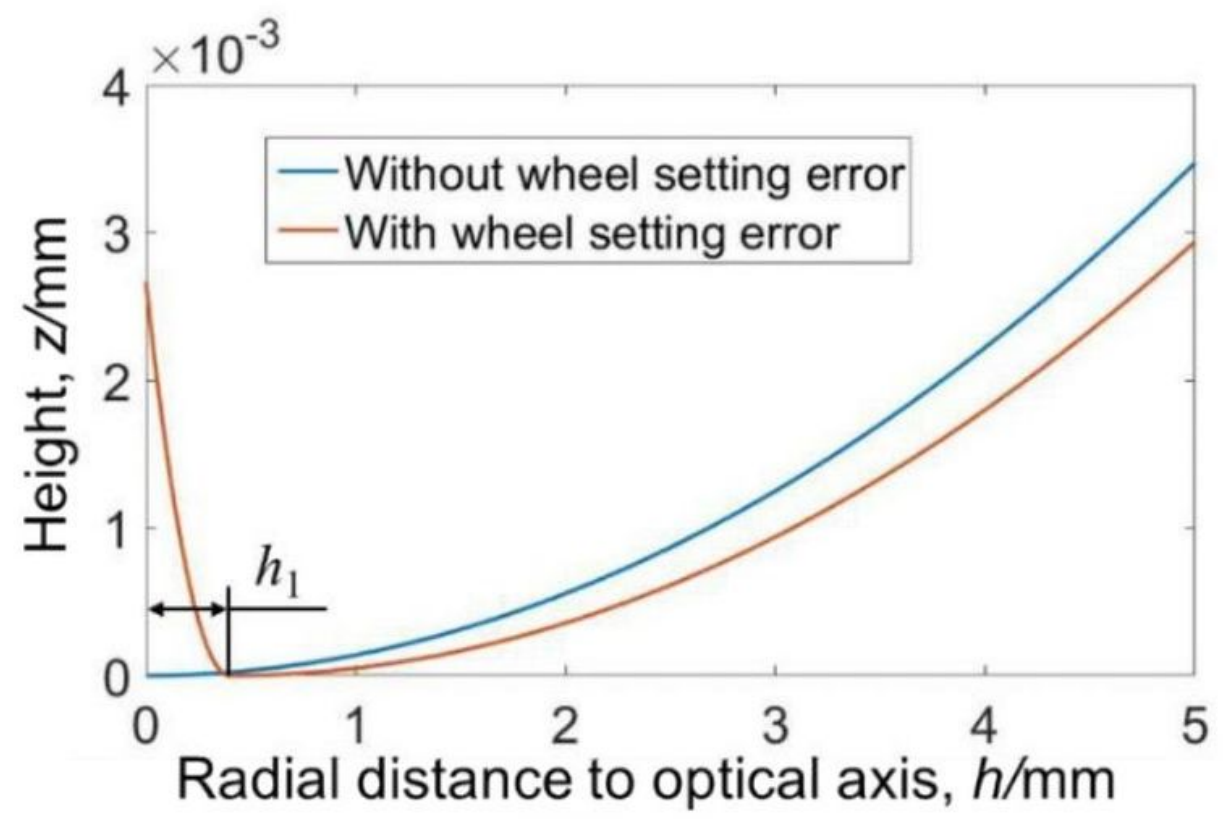

(b) Simulation results

Figure 6

The influence of the wheel setting error along the positive feed direction on the workpiece profile during parallel grinding $(=0.4 \mathrm{~mm})$ 


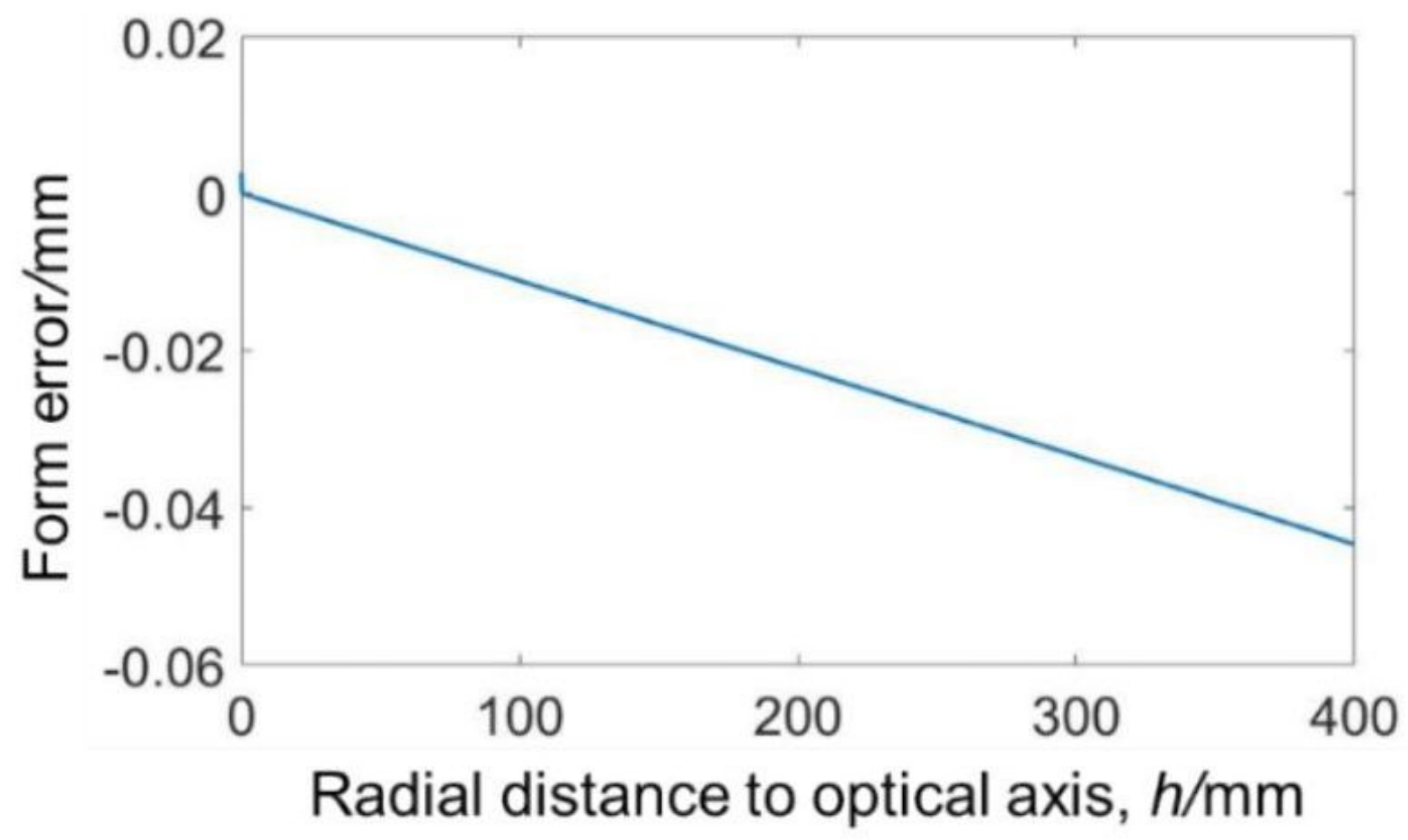

Figure 7

The evolution of the workpiece form error with the radial distance to the optical axis the for $=0.4 \mathrm{~mm}$

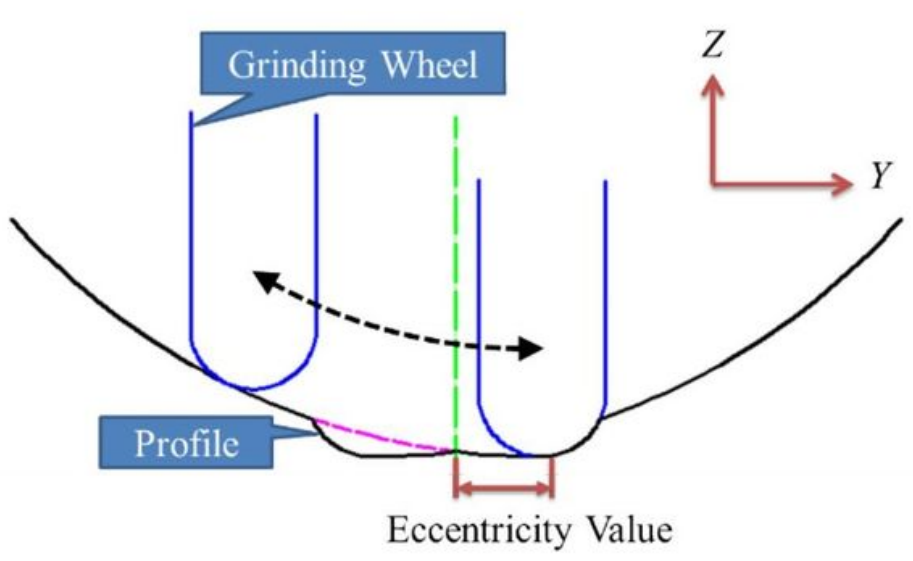

(a) Schematic diagram

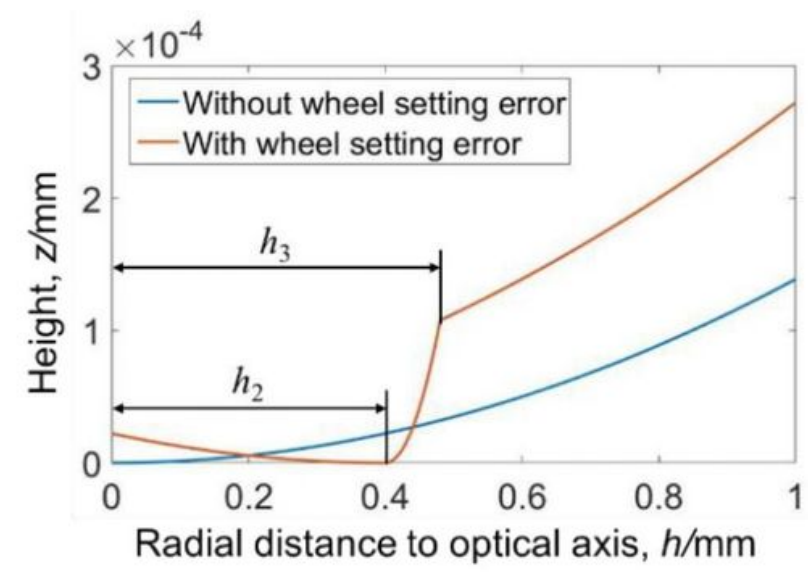

(b) Simulation results

\section{Figure 8}

The influence of the inward wheel setting error on the workpiece profile during parallel grinding $(=-0.4$ $\mathrm{mm})$ 


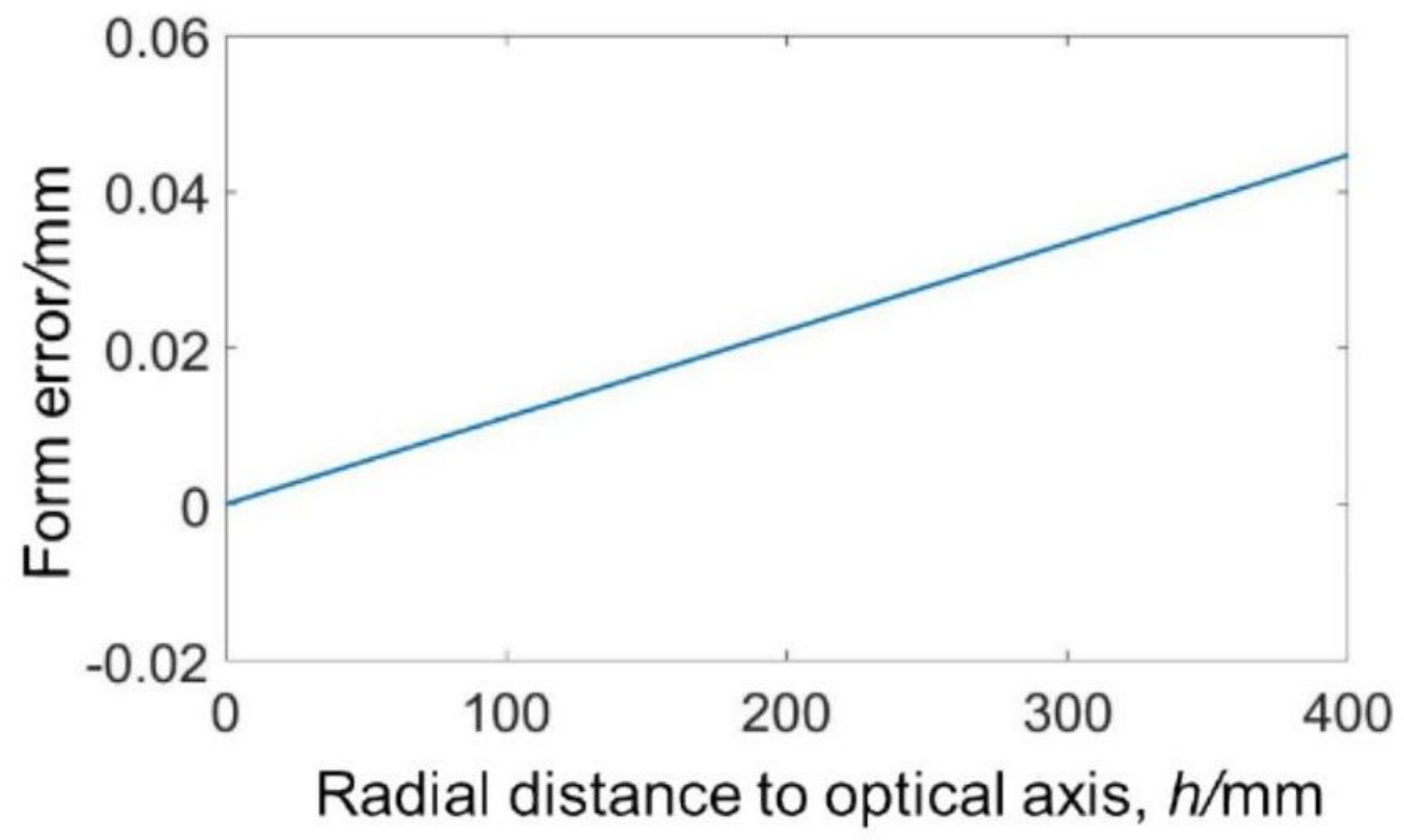

Figure 9

The evolution of the workpiece form error with the radial distance to the optical axis during parallel grinding $(=-0.4 \mathrm{~mm})$ 


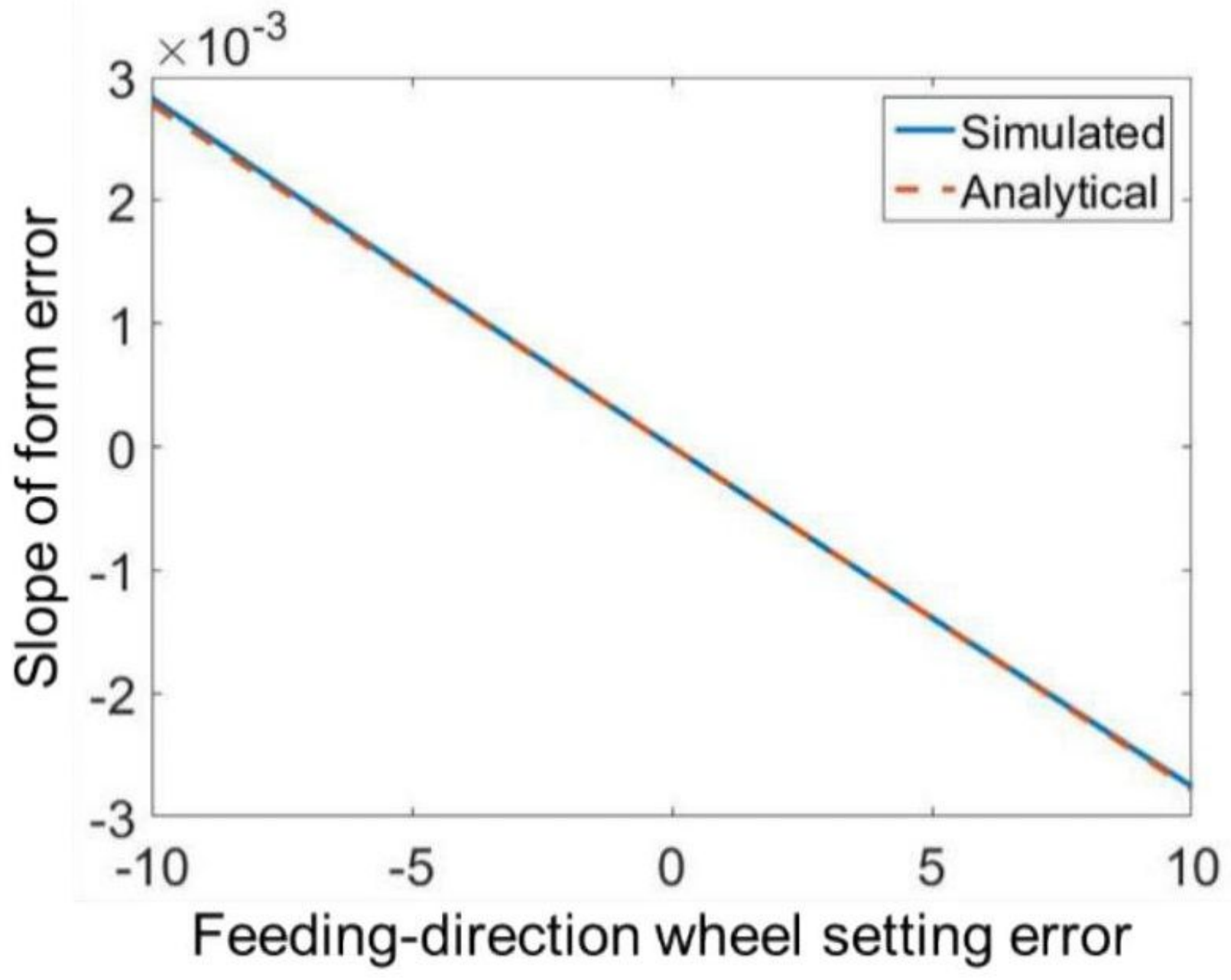

Figure 10

The slope of workpiece form error as a function of the wheel setting error in the feed direction 


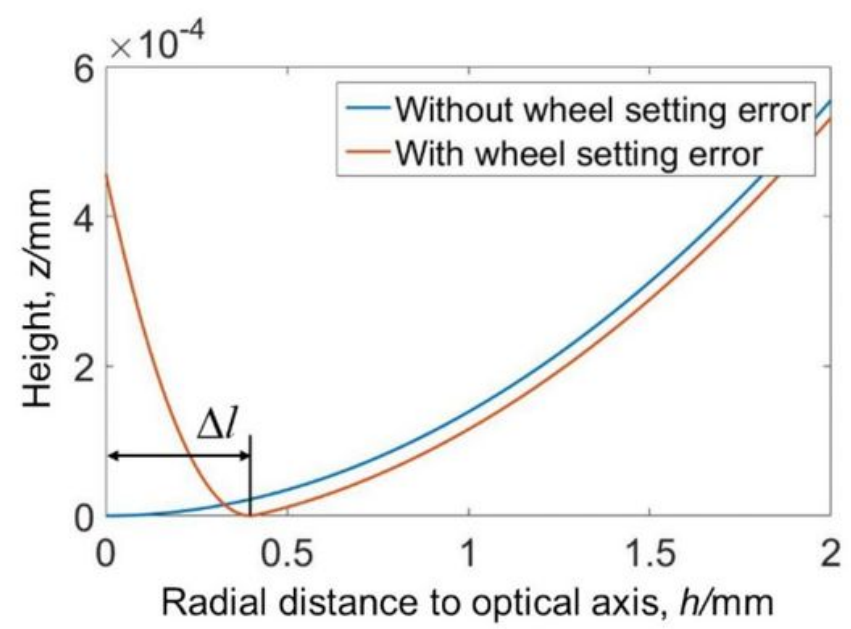

(a) Profiles

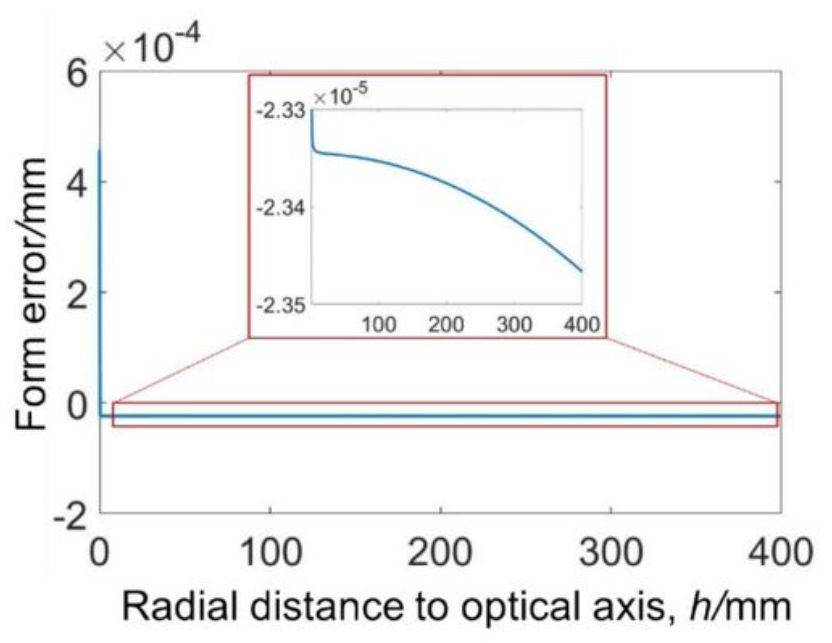

(b) Form error

\section{Figure 11}

The influence of lateral wheel setting error on the workpiece profile for parallel grinding $(=0.4 \mathrm{~mm})$

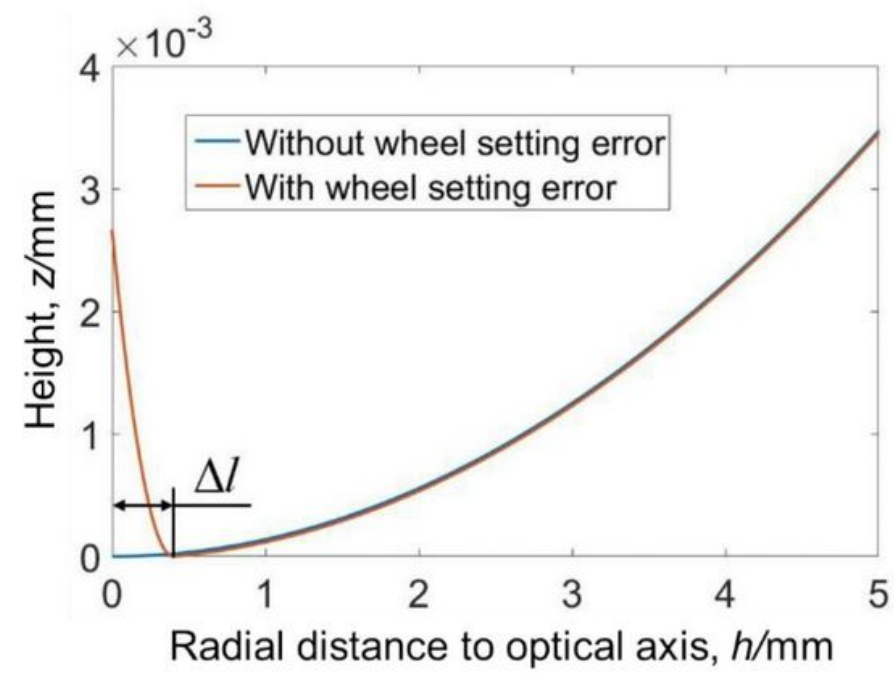

(a) surface profiles

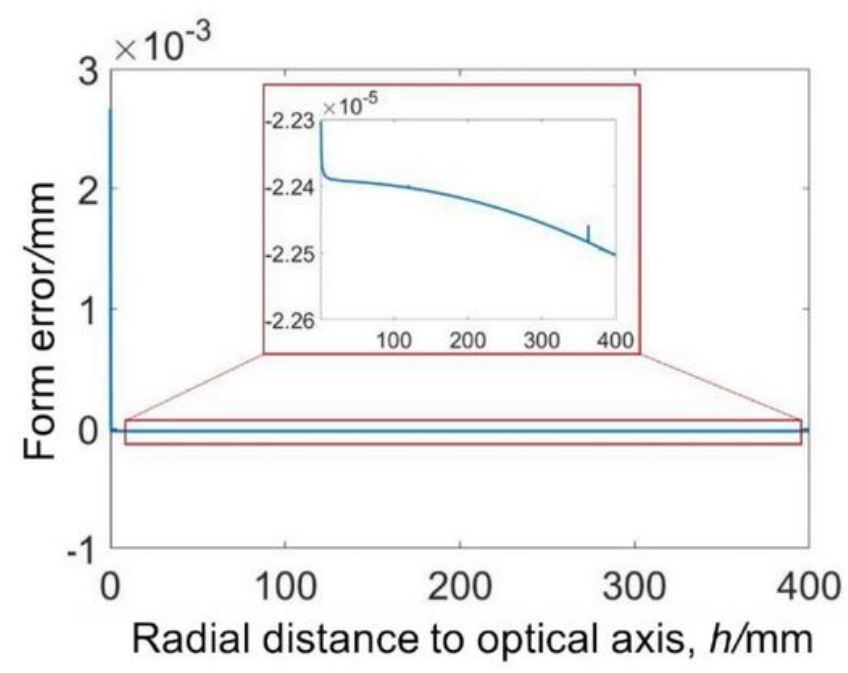

(b) form error

\section{Figure 12}

The workpiece profiles and form error as a function of the lateral wheel setting error during cross grinding $(=0.4 \mathrm{~mm})$ 


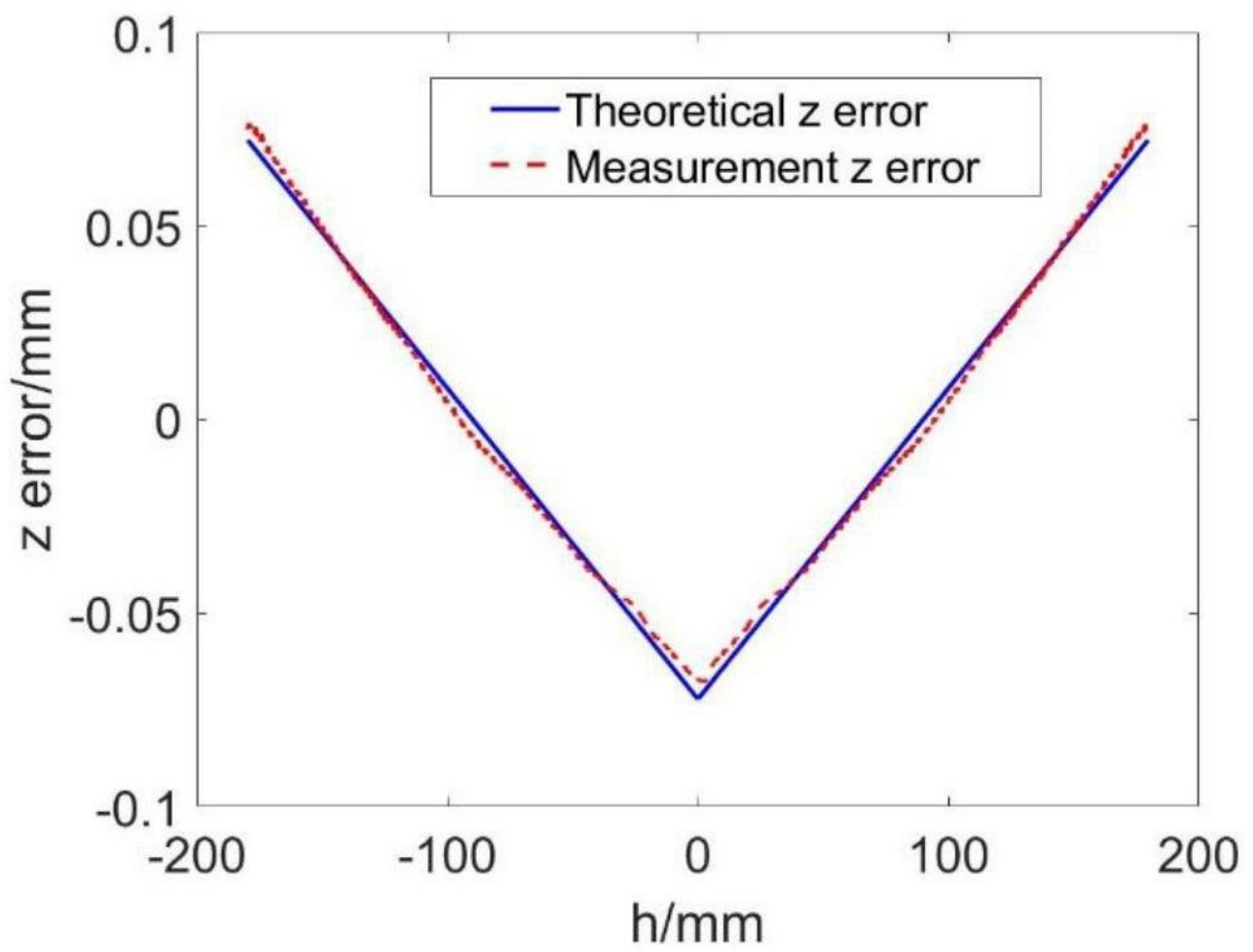

Figure 13

Theoretical and measured error curves caused by the wheel setting error 


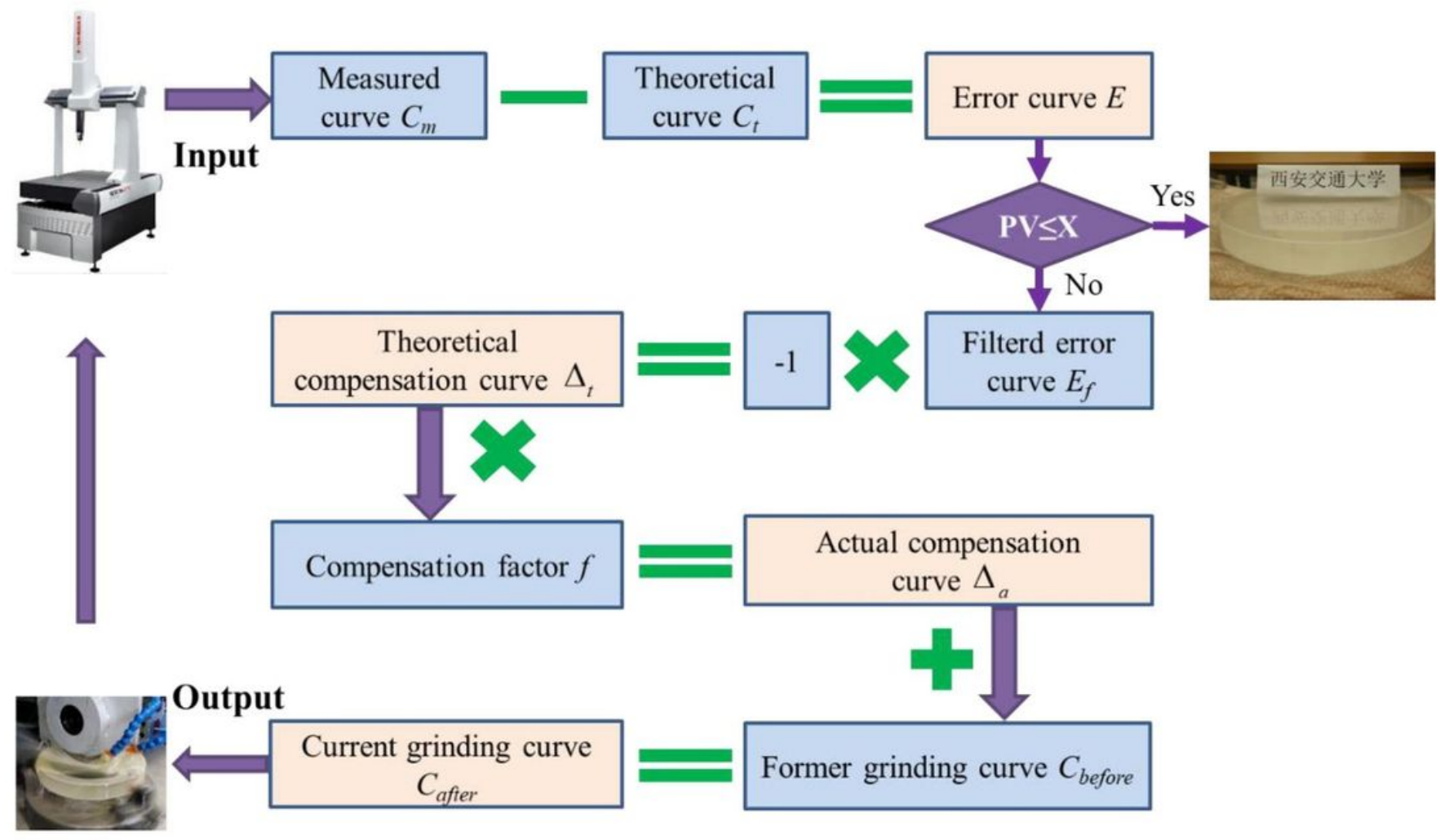

\section{Figure 14}

Error compensation during grinding

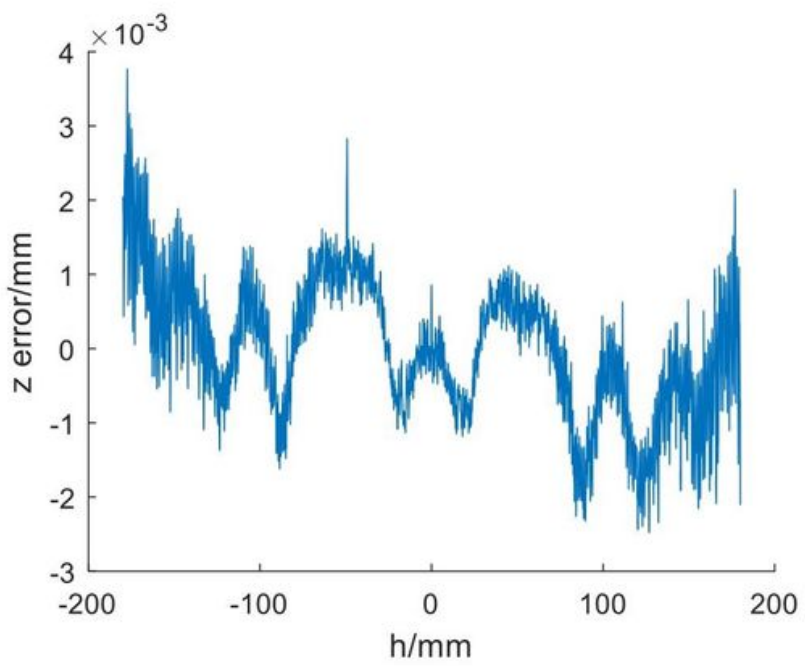

(a) Before correction

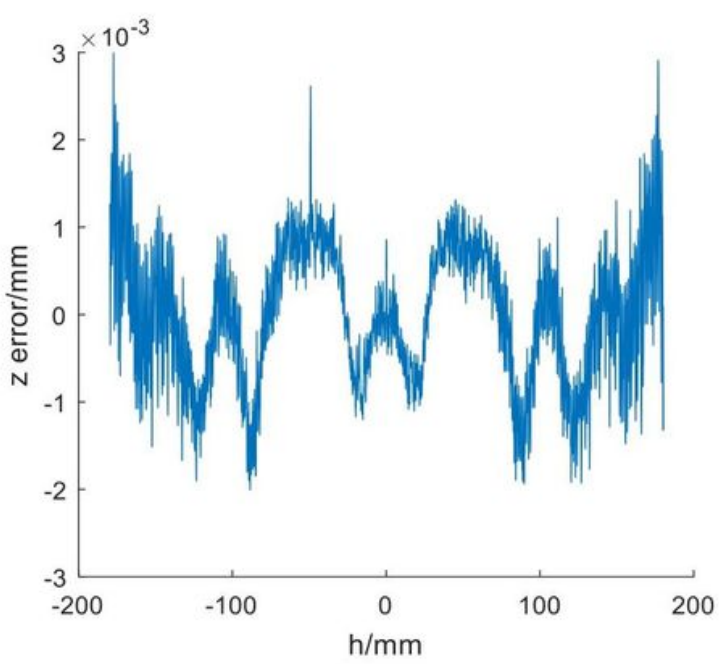

(b) After correction

Figure 15 


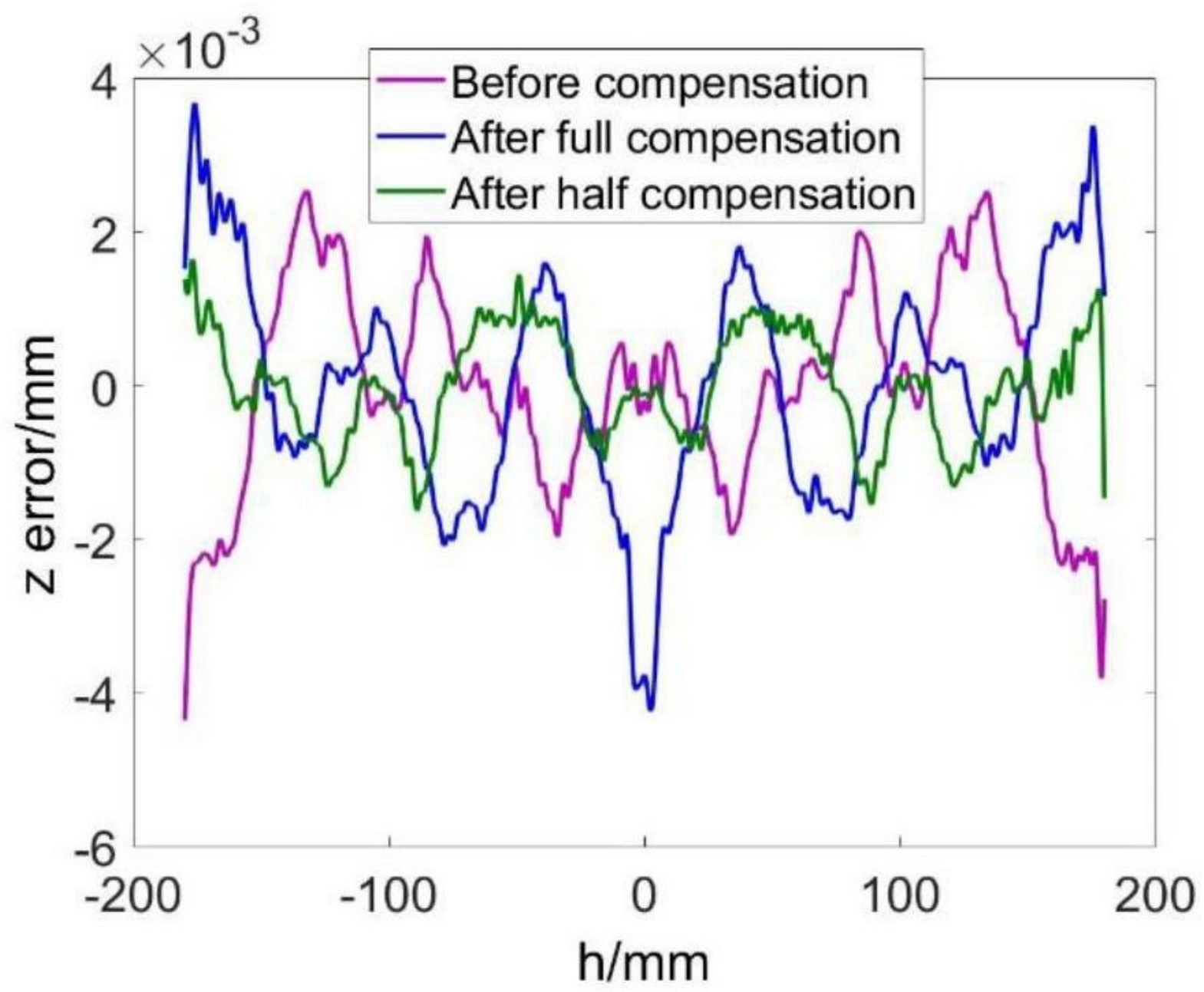

Figure 16

Error curves of workpiece generatrix before and after compensation 


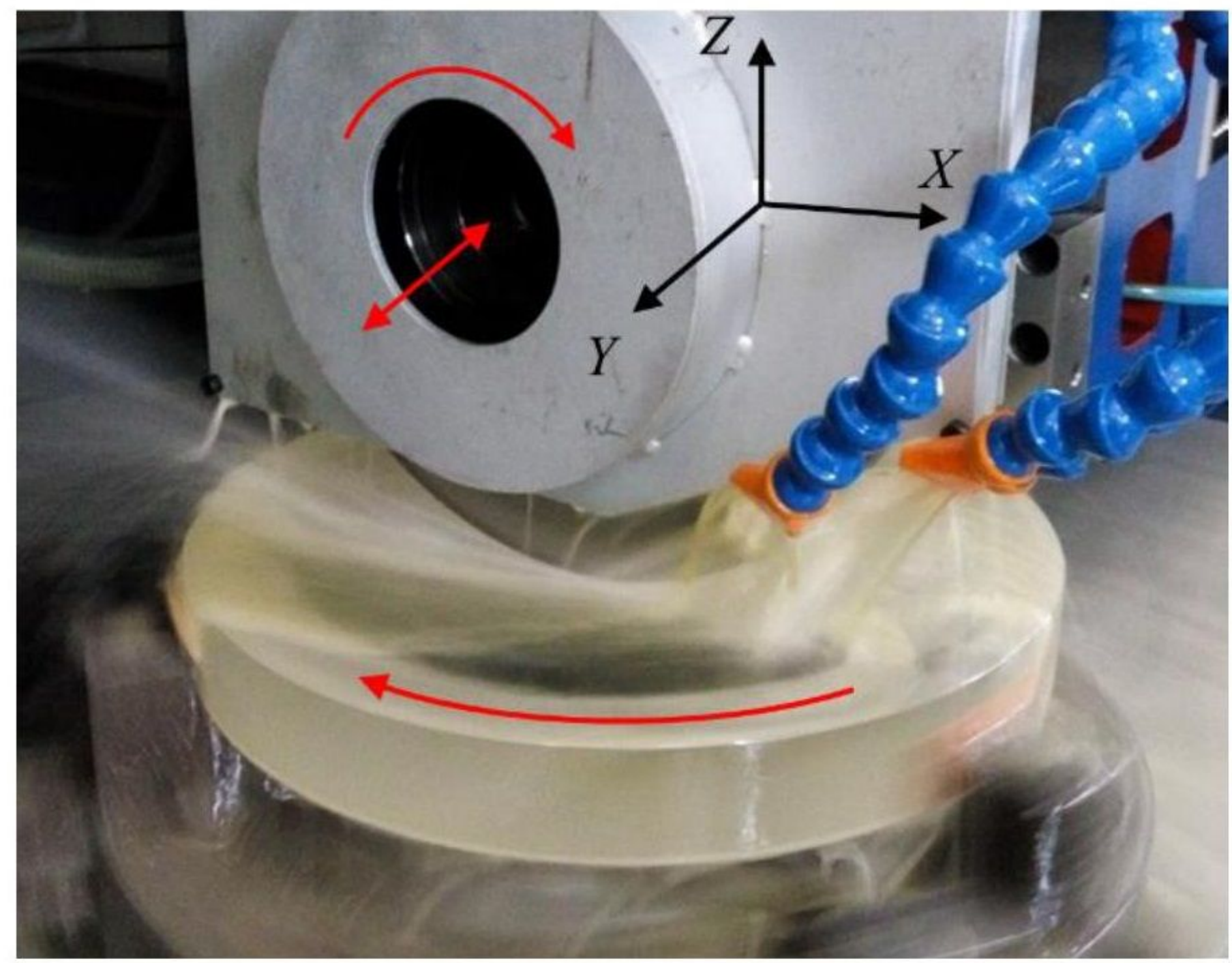

Figure 17

Grinding of a $\Phi 400 \mathrm{~mm} \mathrm{K9}$ glass blank on the CM1500 large grinding machine 


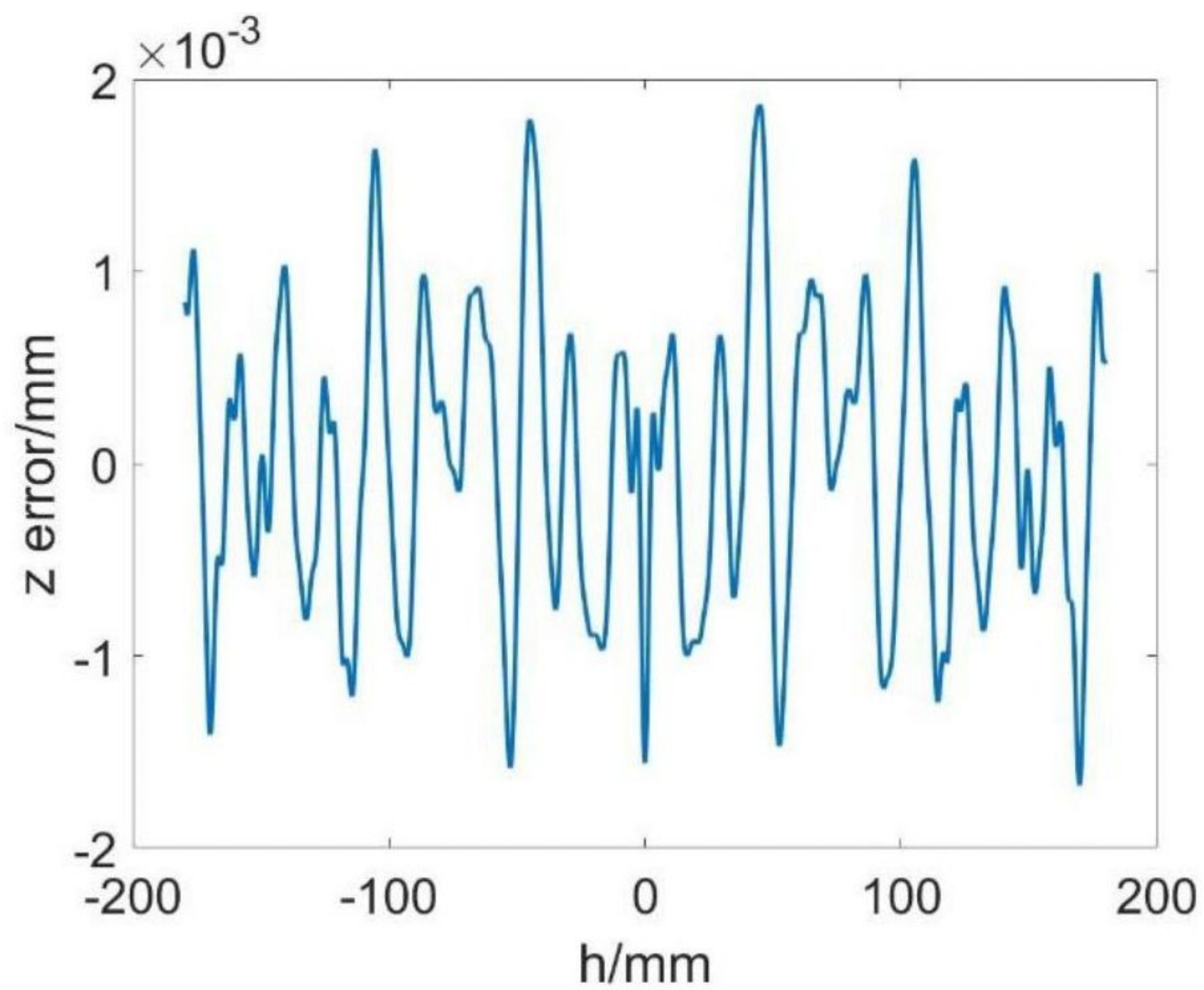

Figure 18

The error curve of an aspherical surface after grinding. It is worth noting that the surface roughness was removed by a low pass filter 